\title{
UCRL-PROC-206279
}

LAW RENCE LIVERMORE N A T IO N A L LABORATORY

\section{Computational Combustion}

C. K. Westbrook, Y. Mizobuchi, T. J. Poinsot, P. J. Smith, J. Warnatz

August 27, 2004

30th International Symposium on Combustion Chicago, IL, United States July 25, 2004 through July 30, 2004 
This document was prepared as an account of work sponsored by an agency of the United States Government. Neither the United States Government nor the University of California nor any of their employees, makes any warranty, express or implied, or assumes any legal liability or responsibility for the accuracy, completeness, or usefulness of any information, apparatus, product, or process disclosed, or represents that its use would not infringe privately owned rights. Reference herein to any specific commercial product, process, or service by trade name, trademark, manufacturer, or otherwise, does not necessarily constitute or imply its endorsement, recommendation, or favoring by the United States Government or the University of California. The views and opinions of authors expressed herein do not necessarily state or reflect those of the United States Government or the University of California, and shall not be used for advertising or product endorsement purposes. 


\title{
Computational Combustion
}

Charles K. Westbrook ${ }^{1}$, Yasuhiro Mizobuchi ${ }^{2}$, Thierry J. Poinsot ${ }^{3}$, Phillip J. Smith ${ }^{4}$, and Jürgen Warnatz ${ }^{5}$

1 Chemistry and Materials Science Department

Lawrence Livermore National Laboratory

Livermore, CA 94550 USA

2 Information Technology Center

Japan Aerospace Exploration Agency

7-44-1 Jindaiji-Higashi, Chofu

Tokyo 182-8522, Japan

3 Institut de mecanique des Fluides

UMR CNRS/INP-UPS 5502

Institut National Polytechnique/ENSEEIHT

Allee du Professeur Camille SOULA

31400 Tolouse, France

$4 \quad$ Department of Chemical and Fuels Engineering

University of Utah

Salt Lake City, UT 84112 USA

$5 \quad$ IWR

Universität Heidelberg

Im Neuenheimer Feld 368

D-69120 Heidelberg, Germany

\begin{abstract}
Progress in the field of computational combustion over the past 50 years is reviewed. Particular attention is given to those classes of models that are common to most system modeling efforts, including fluid dynamics, chemical kinetics, liquid sprays, and turbulent flame models. The developments in combustion modeling are placed into the time-dependent context of the accompanying exponential growth in computer capabilities and Moore's Law. Superimposed on this steady growth, the occasional sudden advances in modeling capabilities are identified and their impacts are discussed. Integration of submodels into system models for spark ignition, diesel and homogeneous charge, compression ignition engines, surface and catalytic combustion, pulse combustion, and detonations are described. Finally, the current state of combustion modeling is illustrated by descriptions of a very large jet lifted 3D turbulent hydrogen flame with direct numerical simulation and 3D large eddy simulations of practical gas burner combustion devices.
\end{abstract}




\section{Introduction}

As the Combustion Institute celebrates its 50th anniversary, it is an interesting coincidence that the science of computer simulation and modeling is also approximately 50 years old. Beginning as a technical curiosity with minor impact on scientific research, computer modeling has grown rapidly to play a major role in virtually every field of science and engineering. In particular, computer modeling is now an essential part of combustion research; at the larger scale, enormous computer simulations are assisting in design and optimization of internal combustion engines, solid fuel rocket motors, industrial burners and furnaces, and gas turbine combustors, using massively parallel supercomputers. At the smaller scale, computer simulations are ubiquitous in everyday combustion life, being used to control operation of individual laboratory experiments, fit spectra in basic science studies, and a multitude of other research and routine applications.

Of course, the electronic computer is not the only modern feature of combustion science. In fact, most of the tools we use today have appeared and become essential during the past 50 years. It is almost impossible today to imagine a research project without the laser, the gas chromatograph or mass spectrometer, and many other tools, in addition to the computer. And each of these tools has grown rapidly in terms of capabilities and importance, although the growth of the computer as a tool has outstripped them all. All of them are indicative of the rapid pace of technological growth, and we must assume that future growth will be at least as rapid and profound. We should continually ask ourselves if we are realizing comparable growth in our understanding of and ability to control the combustion processes that are so much a part of our lives. 
As we will hope to describe in this paper, computer simulations have certainly added a great deal of understanding, providing fundamental answers to many long-standing questions.

Computational combustion is an enormous topic, with many of the different aspects deserving and receiving reviews by themselves. We are attempting to provide an unusual sort of overview, highlighting those areas in which computer simulations have made an important difference in the way we do research, and emphasizing some of the computational contributions that have provided unique and important insights into the nature of combustion itself. These range from cases in which modeling solved longstanding puzzles or problems, to cases in which modeling changed the views of the entire combustion community. We highlight the case of HCCI combustion, where the existence of a mature simulation capability has revolutionized the overall research plan for an industry; the HCCI may or may not make a significant impact on power production, but we emphasize it because it illustrates the nature of the research team of the present and future, and the complete integration of computer modeling into research and development. We finish by taking the pulse of the near future in scientific computing to see what is about to become possible in terms of addressing difficult problems that have never been solved, simply because of their size and complexity. Combustion is one of many disciplines imbedded in a scientific world where the power of the computer is driving much of our progress, and we want to provide a glimpse of the next generation of problems that will be enabled just by continued growth in computer capacity. 
This review is necessarily unbalanced; for example, we focus on modeling of laminar premixed flames and devote no space to laminar diffusion flames. We also discuss models of internal combustion engines but omit gas turbines and furnaces. The inclusions and exclusions reflect the strengths and weaknesses in the experiences of the authors, and they also are motivated by the limited space and time available to us. However, we have tried to include those areas in which computer modeling has grown and then made significant technical advances. In some cases, our choices were simplified by the existence of a recent expert review in some area that we could cite for those interested in further information. Our brief comments on soot modeling and modeling based on asymptotic analysis may be excused because we have assumed they will be discussed at length in one or more of the other review papers in this conference.

\section{Background}

Although computer modeling could not exist before the development of the computer, many essential tools were already in place before the arrival of the ENIAC and UNIVAC in 1952-1956. A considerable literature dealing with finite difference methods of solving differential equations had been developed, beginning with the paper of Courant, Friedrichs and Lewy in 1928 [1]. The solution techniques of Gaussian elimination for solution of simultaneous linear equations and Runge-Kutta methods for solving ordinary differential equations were also established before the arrival of the electronic computer [2]. There was also an enormous literature of careful, insightful experimental data for laminar flames, chemical kinetics, radiation tranport, detonations, and many other problems; much of this experimental data and the technical insights based on 
these experiments were used in developing early numerical combustion models, and much of the same data is still waiting for computational combustion analysis.

The key person in the development of the first computers was John von Neumann, whose experience with transport and reactive flow problems led him to propose a concerted development effort following the end of the Second World War to produce an electronic computing machine, which was built at Princeton's Institute for Advanced Studies between 1946 and 1952. Ever since, scientific computing has been a discipline where researchers specialize in formulating problems that they know they cannot yet solve, although they know that the time will come when computer capabilities will catch up with their needs; of course, by the time they can actually complete that calculation, they will have again set their sights much higher, to another problem that cannot yet be solved. Scientific computing invented its own term for such problems, "Grand Challenges". At Supercomputing 88 [3], sixteen years ago, the problems identified as unsolvable but important included aerodynamic flows over vehicles and through engines, and in-cylinder combustion flowfields, in addition to problems in many other fields, including the computing required to complete the human genome; in 2004, many of those problems are well on their way to solution, and people are formulating the next generation of Grand Challenge problems that cannot even be attempted today.

Perhaps the most dramatic example of computer readiness before the invention of the computer was provided by Lewis Richardson, who invented the entire theory of the massively parallel, multi-physics, spatial grid-based, timestepping solution of huge sets of coupled partial differential equations that we 
use today, when in 1922 he published his book Weather Prediction by Numerical Process [4]. Richardson described an operator split simulation of the weather in northern Europe carried out by thousands of people using slide rules and adding machines. These people (today we might call them CPU's) would sit in an enormous theater or auditorium (he gave, as an example, the Albert Hall in London), each one solving one piece of one equation and passing the result to the next person in line to solve the next equation. Coordination would be expedited by an orchestra-like conductor and results would be communicated by motorcycles traveling along each aisle. Richardson actually carried out one full 6-hour time step of his model, which he did by himself while an ambulance driver in World War I. He estimated that with 64,000 calculators (i.e., people), it might be possible to "break even" and complete a 6-hour weather simulation in 6 hours of calculating time. Richardson's solution was not accurate, largely because it lacked reliable initial values for the important variables, and it would have become unstable because the importance of the Courant limit for the timestep in his explicit calculation was not yet understood. However, the same model with better initialization conditions and time step control has subsequently been shown [5] to provide good weather predictions.

When the first computers for civilian use were developed in the early 1950 's, meteorology and weather prediction became one of the first major application subjects [6,7], followed quickly by astrophysics [8], plasma physics [9], and eventually by combustion. Los Alamos National Laboratory (LANL) and Lawrence Livermore National Laboratory (LLNL) played central roles in the development of the computer and of computer models; for most of the past 50 years, LANL and LLNL regularly received the first copy of each new class of 
supercomputer, from the UNIVAC 1 in 1953 to the BlueGene L computer from IBM currently being installed at LLNL. As a result, many innovations in model development can trace their history to these laboratories.

In particular, much of the pioneering work in Computational Fluid Dynamics (CFD) was carried out at Los Alamos where von Neumann and others developed the stability analysis methods that have contributed so much and are so widely used as the basis for analyzing linearized systems of partial differential equations. In 1965 Harlow and Fromm [10] marked the beginning of the CFD era with an article in Scientific American where the ideas of computer "experiments" and numerical simulation were first introduced. In this regard, the many contributions of Harlow and the T3 group at Los Alamos are remarkable, particularly due to their influence on CFD-based combustion furnace simulations. Three important advances exemplify the contributions of this group:

1. The first development of the pressure Poisson equation [11] that allowed for the solution of the Navier-Stokes equations written in terms of the primitive variables, velocity and pressure. This allowed explicit methods to make time steps commensurate with the convection speed instead of being constrained to time steps small enough to resolve the sound speed. It became the basis for steady-state methods from which essentially all combustion furnace calculations were built. This development was the genesis of what later became pressure projection methods that are used in nearly all modern CFD-based combustion simulations.

2. The first CFD-based development and application of the k- $\varepsilon$ model for turbulence [12]. Although this model was made famous by Launder and 
Spalding [13], they credit the Los Alamos group with its origin in their now famous lecture notes. This turbulence model has been the most extensively used of all turbulence models used for combustion simulation applications.

3. The development of several combustion simulation codes of which perhaps KIVA [14,15] has been the most widely distributed. It has become a standard for Internal Combustion Engine combustion applications.

Spalding and colleagues at Imperial College in London did the pioneering work of building the first combustion simulations on the CFD base from Los Alamos. The TEACH code resulted in a widespread dissemination of these types of calculations, and the methods $[16,17]$ adopted, developed and practiced at Imperial College in the late 1960's through the 1970's found their way into virtually all of the major commercial CFD codes on the market today.

\section{Moore's Law}

In 1965, Gordon Moore of the Intel Corporation [18] observed that computer capabilities had been growing exponentially, doubling every 18 to 24 months. The principle of exponential growth in computing capabilities has become known as Moore's Law, and whether evaluated in terms of the number of transistors per planar integrated circuit as noted by Moore, or by the number of floating operations per second (flops), this growth has continued to this date, as shown in Figure 1. In fact, recent advances in massively parallel computing and related technologies have further accelerated growth in computing power. The Earth Simulator computer made by NEC and placed in service in Japan in 2002 established itself at that time as the fastest computer in the world at 40 
TeraFlops. Based on current projections for the next several years, this rate of growth shows no signs of slowing. From a combustion modeling point of view, this growth represents a challenge to find ways of utilizing this capability in a productive way.

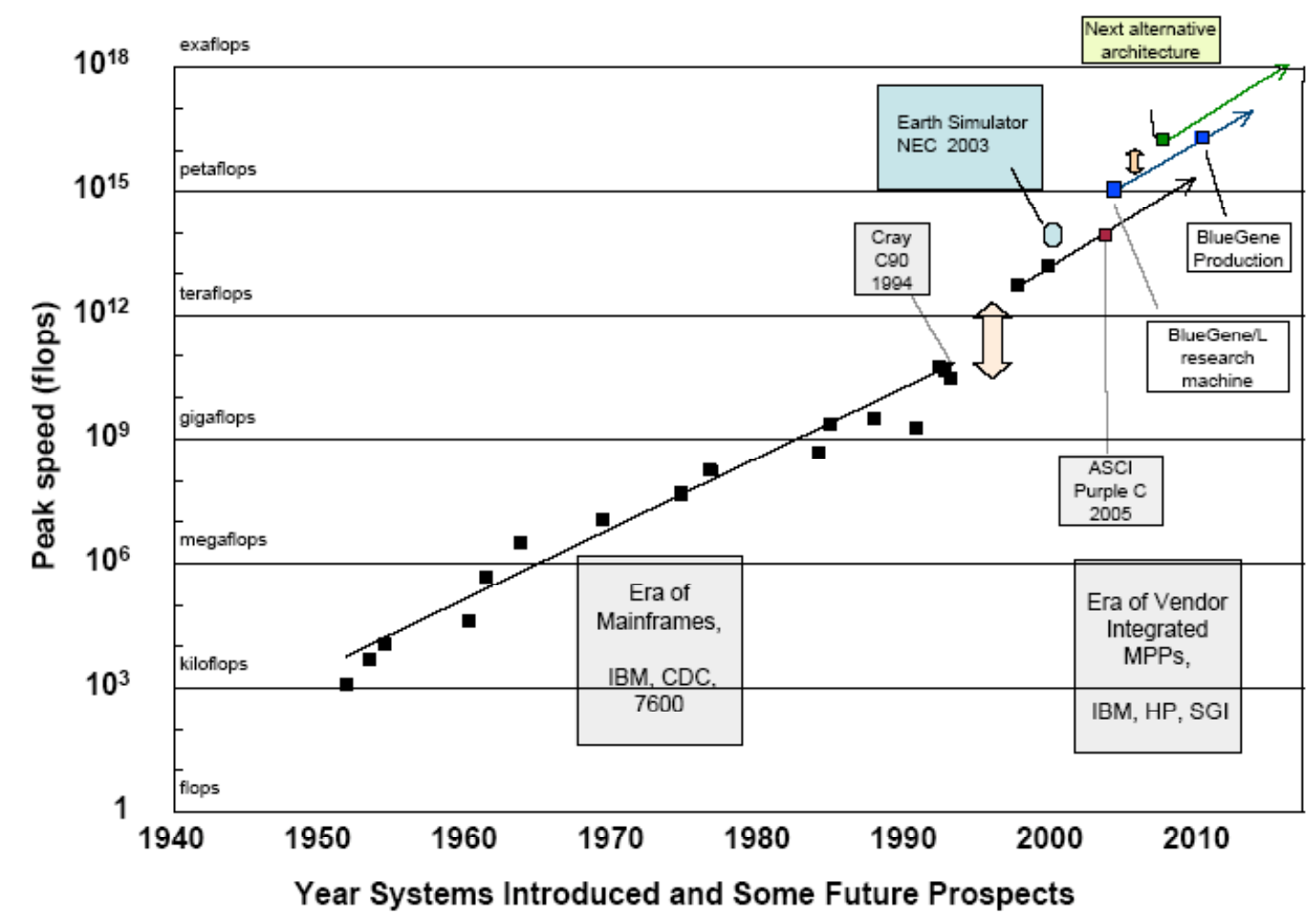

Figure 1. Illustration of Moore's Law, showing computer speed as a function of calendar year

\section{Growth of combustion modeling}

This continual growth in computing power has been the single greatest factor in a corresponding increase in the size and complexity of combustion 
models. Growth can be measured in terms of the number of computational gridpoints in CFD calculations, in the number of chemical species in chemical kinetic models, in the spatial resolution of direct numerical simulations (DNS) of turbulent flows, or in the number of reactive surface sites in a CVD or surface combustion simulation. More generally, increasing computer power enables combustion models to include a much greater level of complexity and realism in simulations. This has made it possible to include more coupled physical and chemical processes in a single model, simultaneously treating problems with different combinations of greater spatial resolution, more chemical species, a more complex turbulence model, a more sophisticated radiation model, multiple

phase phenomena such as a spray model or a soot model, or moving objects such as intake valves or piston blades.

Superimposed on steady increases in capabilities provided by growing computing capacity, individual innovations have made rather sudden and unanticipated contributions to combustion modeling, providing new functionalities that have been extremely important. In this paper we will attempt to document both the steady and the occasional, unpredictable growth in the ability of the combustion modeling community to simulate and interpret real-life applied problems.

\section{Partial Modeling}

In his introduction to a Colloquium on Modeling Principles at the 9th Symposium in 1962 [19], Brian Spalding noted that “...except in rare cases, 
combustion modeling is impossible; already the number of set-up rules to be obeyed exceeds the degrees of freedom at the disposal of the experimenter; and, in addition, the requirements of cheapness, speed, and accuracy have to be met." The set-up rules he cites require that the relevant dimensionless parameters of the system to be modeled must be similar to those in the experiments on which the model is to be based. In particular these would include the Reynolds number, Mach number, Froude number, Lewis number, Prandtl number, Schmidt number and the geometrical features of a given problem. Spalding goes on to say "Thus nearly all currently used combustion models are examples of partial modeling, in which only a few of the rules are obeyed; the disregard of the others inevitably introduces some uncertainty about how the results of the experiments should be interpreted.... The central problem of partial modeling is to discern which modeling rules need not be obeyed, and to estimate the resulting errors in the predictions which are made $\quad . .$. which necessitates a high degree of physical insight and inspired guesswork on the part of the experimenter; it is for this reason that the word "art" has been included in the title of the present paper."

Spalding observes that for some predictions, knowledge of the entire combustion system is not essential and that the impact of some parts of the system are much more dominant than others. He concludes with "The skill of the modeler, and his good fortune, are measured by the extent to which he is able to sort out the variables and phenomena with which he is concerned into semiindependent sets. Sometimes this separation is suggested by a study of the differential equations; more often its existence is perceived intuitively, or even assumed unthinkingly as a result of blissful ignorance." The principles described 
by Spalding remain operational today for "partial modeling" using computer simulations.

The remainder of the Ninth Symposium colloquium consisted of examples of partial modeling applied to such systems as buoyant flames, crib fires, aircraft gas turbines, coal-burning jet fires, a jet engine afterburner, ramjet combustors, liquid and solid fuel rocket motors, and various classes of chemical reactors. All of the "models" discussed consisted of scaling results from one system to another, related system using the relevant dimensionless parameters. Many of the studies used non-combusting or "cold" flows, frequently water, in the experiments and then extrapolated to burning conditions on the basis of dimensionless parameter scaling. Perhaps most interesting, all of these papers dealt with practical, applied combustion systems that today we might call "too complicated" for current modeling capabilities.

In spite of all the changes in combustion science in the past 50 years, "partial modeling" is still pursued in computational combustion, although it means something a little bit different from the usage of Spalding in 1962. Today, it means focusing on one specific process that we can study computationally in considerable detail, separated from other factors that might also be occurring. There are many examples of this approach that we now take for granted. For example, flamelet approaches to turbulent combustion focus very narrowly on a very small element of the turbulent environment. Flame-wall interactions treat flame quenching as if no other processes were taking place in the combustor. We calculate droplet vaporization rates by modeling a single droplet in a flow with steady flow speed and direction. Most laboratory experimental combustion 
studies are intended to focus on only one or two specific processes and are equivalent to partial modeling.

The second general modeling approach can be called "full system modeling" in which as many as possible of the processes in the combustor being modeled are included. Even full system models usually reduce the degree of complexity by making simplifying assumptions. Two and three dimensional CFD engine simulations usually include simplified chemical kinetics submodels, simplified turbulence models, little or no radiation submodel, and other engine simulations greatly simplify the problem geometry by assuming the combustion has two-dimensional symmetry. An exciting feature of computational combustion today is that new computer capabilities are making it possible to include more submodels and more complexity in system models, approaching true full-system modeling capability.

The Colloquium on Modeling Principles in 1962 marked the culmination of the first generation of combustion "modeling", which was terminated effectively by the entry of the electronic computer into the research environment. This early period was dominated by the use of scaling laws using dimensionless parameters to interpret and extrapolate specific experimental observations to other conditions. Combustion scientists trained in these techniques became expert in the applications of such modeling (or scaling) techniques and used them to great advantage. For example, in another paper at the same Ninth Symposium by Becker et al. [20] entitled "Mixing and Flow in Ducted Turbulent Jets", dealing with conditions in industrial furnaces, the first sentence following the Introduction is the following: "It is well known that fully turbulent constantdensity jets in infinite stagnant atmospheres are aerodynamically similar". This 
sentence stated the rules of engagement for their analysis and permitted the authors to use the principle of self-similarity to carry out the analysis. It is effectively equivalent today to starting a paper by stating "We used the Chemkin PREMIX code to study the following combustion system."

Many of the most successful first-generation "modelers" eventually adopted the computer-based modeling paradigm with enthusiasm and great success. There is always a suspicion that these early combustion scientists "understood" combustion more thoroughly and more viscerally than researchers today, who study combustion using detailed computer simulations and laser diagnostics. The combustion community should regard the general development of combustion codes with great care to avoid losing touch with the fundamental features of real combustion problems and applications. This is particularly relevant today; while most combustion models between 1965 and about 1990 were used by the same people who wrote and built the models and were doing the experiments, in recent years there has been a significant evolution towards use of codes written by others and often prepackaged by commercial software vendors. While such modern models enable researchers to save enormous amounts of time and effort in their analysis, it is very easy to apply such models to systems in which they are not valid or relevant, and for the code user to lose tangible contact with the combustion system.

The remainder of this paper is presented in two sections. The first consists of discussions of specific chemical and physics processes and how computational models for them have been developed. The second section discusses examples of current simulation capabilities, with illustrations of selected examples. Extensive 
references to further material are provided when possible, but in many subjects the literature is enormous and only representative examples are cited. These discussions are necessarily limited by available space, and not every type of system is included.

\section{Fluid Mechanics}

Most computational combustion models are built upon a base of fluid mechanics. The basic numerical methods of computational fluid dynamics (CFD) were developed first at LANL and LLNL by Hirt, Harlow, Noh, Leith, Butler, and others. A very good review of the overall history and principles of CFD is by Roache [21]. Some of the early CFD models developed included the CEL (Coupled Eulerian-Lagrangian) [22], ICE (Implicit Continuous-Fluid Eulerian) [23], RICE (Reactive ICE) [24], ALE (Arbitrary Lagrangian-Eulerian) [25], CONCHAS [26], and KIVA [14,15]. Although first intended for classified applications to solve problems in plasma physics, nuclear reactions, and radiation and neutron transport, these reactive CFD models were then adapted for new applications in other fields, particularly in atmospheric modeling and astrophysics, and increasingly as the basis of new combustion models.

We have already noted the important role of Spalding and colleagues at Imperial College in adapting these CFD methods to combustion problems. Additional research in this area extended the techniques to deal with chemically reactive systems [27] by making the algorithms more implicit. At about this same time, the concept of "operator splitting" was developed [28], which made it possible to include any number of nearly independent processes coupled to the CFD model. As a result, system models were able to include, on top of the CFD 
simulation, such processes as spray evolution, chemical kinetics and heat release, radiation transport, moving boundaries, and many others.

In recent years, the extreme diversity of CFD methods has become considerably consolidated into a much smaller set of commonly used models. The complexity of 3D fluid mechanics has made it necessary to simplify the algorithms and has made computer science as important as the fluid mechanics. One of the most familiar and widely used 3D code frameworks is the KIVA model with its relatively simple regular, structured meshes. However, unstructured grids offer the advantage of being more suitable to massively parallel computing environments, as well as an ability to deal with complex geometries. The extra computational costs of using unstructured meshes are often worth investing in order to analyze complex problems, and many commercial CFD codes now use unstructured grid formulations. Commercial combustion codes have become so capable that many code developers are now coupling their physics and chemistry submodels to them. This includes soot formation models, reduced kinetic models, surface chemistry, plasma and charged particle models, all of which are being integrated into the CFD environment of commercial models. An extended list of commercial and free CFD softward is available on the web [29], including home pages for each company and descriptions of their special focus areas and other useful material. It is interesting to discover how many of these companies trace their origins to the first generation of CFD modelers at Los Alamos and Lawrence Livermore.

\section{Radiation transport}


A significant milestone in the early evolution of combustion simulation was the development of the Hottel Zone Method for radiative heat transfer and its subsequent use in furnace calculations. Since the role of combustion in practical systems is often to provide a radiative energy source, many of the earliest models of combustion focused on radiative heat transfer. Hoyt Hottel of MIT was an early advocate for combustion furnace analysis through radiative heat transfer aspects of calculation. In these 1960's vintage analyses, the emphasis was on identifying an approach tht would be tractable on a thencurrent computing machine. The philosophy of the approach is seen in this quote from Hottel and Sarofim [30]:

"If the previous chapters have given the impression that the authors favor rigorous analysis of problems, here is the place to underline the statement that, in engineering, unnecessary rigor is more often than not a sign of bad judgment. Visualize an industial furnace burning pulverized coal for the purpose of transferring heat to water-cooled walls, and consider the complex picture of the furnace interior (perhaps as large as a small lecture hall) as seen through a peephole. One needs no background of experience or vivid imagination to conclude that the details of the process of transfer of energy from the entgering fuel and air to the heat-sink surfaces disposed on the walls - involving as they do a combination of problems in fluid mechanics, molecular and turbulent diffusion, chemical kinetics, radiation from solid particles and from gases, absorption of radiation by those same particles and gases, reradiation from refractory surfaces, natural and forced convection, wall conduction, et al. - are not susceptible of rigorous mathematical representation. Even if an analysis of a reasonably complex model were feasible, that would not be the place to start on the problem. The human mind visualizes a function of two variables with some facility because it is representable as a family of curves. A function of three variables is beyond the capacity of most good minds to visualize; and fairly simple derived functions of that function definitely beyond all - except by the process of holding constant one variable at a time. It is clear, then, that either improvements of a particular furnace design or imaginative changes in the basic features of the design are most effectively stimulated by mathematical models of the process which are the simplest possible consistent with realism - those which include only the key variables. This is not to say that one should stop short of allowing for factors of significance just because there are so many of them. But it is usually the part of good engineering to construct 
the simpler model first, use it to test whether the variables are significant, and then perhaps construct a more complete model."

This paragraph is the introduction to the description of the zone models for furnaces. The number of zones being constrained by the computational effort that could be accomplished on computers of the era. The paragraph is noteworthy for the early recognition of several central challenges for combustion simulations:

1. The recognition of the multi-physics, multi-scale nature of combustion simulation.

2. The recognition of the need to first identify the intended use of a mathematical model in order to prioritize the simplification of the physics to be included in the model.

3. The recognition of the difficulty associated with simulation visualization; specifically, how to present to the human mind the nonlinear effects of the multi-variate combustion simulations.

4. The identification of the snowball effect of simulation science; namely, the growth from simpler to more complex models as computational power grows.

5. The need for a validation science to grow in parallel with simulations.

The Zone Modelling approach introduced by Hottel and Sarofim became the mainstay of industrial combustion analysis for the next 20 years for design of power generation boilers and industrial process heaters.

\section{Combustion chemistry modeling}

\section{$\underline{\text { Stiff Equation Solvers }}$}

Simulation of the chemical reactions that release heat and drive the combustion flows is frequently the most computationally demanding part of a full combustion model. In the most common formulation, a time dependent 
differential equation is written for the concentration or mole fraction of each chemical species in the system being studied. These coupled equations frequently have widely disparate characteristic time scales, referred to as "stiffness", and common techniques for their solution are generally ineffective. The first numerical solution method for stiff differential equations of coupled chemical kinetics was developed in 1952 by Curtiss and Hirschfelder [32]. In 1969, the first automated computational techniques for solution of stiff systems of coupled differential equations were developed by Gear [33,34] and implemented in multipurpose software by Hindmarsh and collaborators between 1974 and 1980 [35,36]. Other stiff equation solvers soon followed, and excellent reviews of this topic have been provided [37-39]. Although first developed for atmospheric chemistry problems, the same software could then be applied to the even more stiff kinetic equations of combustion chemistry applications. Today, 40 years after their original introduction, many of the same techniques for solving stiff equation solvers are widely used in models for chemically reactive systems.

The timing of the development of general-purpose software for integrating stiff kinetic equations was very important. As we will show below, attempts to model laminar flames were severely challenged before about 1975 because it was so difficult to solve the stiff kinetic equations. As a result, most flame models had to address only simple kinetic systems or had to make assumptions of quasi-equilibrium for radical species. It is no coincidence that kinetic modeling suddenly moved forward once the stiff equation solvers were available. This is one of the sudden advances in capabilities that had an enormous impact on computational combustion. 


\section{Hierarchical mechanisms}

The first chemical kinetic systems to be modeled were for ozone [40] and hydrazine [41] decomposition and then for $\mathrm{H}_{2}$ combustion, which consists of no more than 10 chemical species and 20 elementary reactions. By about 1970, the first hydrocarbon fuel kinetic models were being developed, primarily for methane $\mathrm{CH}_{4}[42-46]$ and then for methanol $[47,48]$. The appearance of stiff kinetic equation solvers about 1970 clearly enabled the ability of models to deal with larger hydrocarbon reaction mechanisms with more varied time scales. The methane oxidation mechanism initially appeared to be deceptively simple, consisting of methane producing methyl radicals via $\mathrm{H}$ atom abstraction, followed by conversion of methyl to formaldehyde $\left(\mathrm{CH}_{2} \mathrm{O}\right)$, then formyl $(\mathrm{HCO})$ and $\mathrm{CO}$, and ultimately to $\mathrm{CO}_{2}$. While the apparent simplicity of the methane kinetic mechanism was eventually found to be incorrect, the most important combustion chemistry modeling product of this period was the realization that the kinetic models for hydrocarbon fuels could be built in a logical, hierarchical manner $[49,50]$ where the kinetic mechanism for any fuel has, as a subset, the reaction mechanisms for all of the possible smaller molecule fuels. This means that when a mechanism for the next, larger and more complex fuel species is needed, only the species and reactions for the new species are needed, since all of the underlying mechanism should be largely unchanged and needs no further attention. This reduces dramatically the time and effort required to develop a large species reaction mechanism. 
The other major discovery [51] was that methane combustion chemistry was complicated by recombination of methyl radicals to produce ethane $\left(\mathrm{C}_{2} \mathrm{H}_{6}\right)$, followed by consumption to produce ethene and acetylene, until finally $\mathrm{H}_{2} \mathrm{O}$ and $\mathrm{CO}_{2}$ are produced. A special American Chemical Society meeting session in 1977 [52], organized by Bill Gardiner and David Edelson, focused attention on the kinetic modeling of methane combustion and was especially influential in establishing a common basis for this type of modeling and recognizing the complexities of the kinetics of this most fundamental hydrocarbon fuel.

The oddities of methane oxidation kinetics have had many important implications in the years since this conference in 1977. Because methyl radicals do not directly produce $\mathrm{H}$ atoms like all larger alkyl radicals, methane is unusually resistant to ignition; however, addition to methane of very small amounts of other hydrocarbons, especially ethane or propane, dramatically increases the ease of igniting methane [53]. For this simple reason, combustion characteristics of natural gas (which usually consists of more than $90 \%$ methane, the remainder being primarily ethane and propane) that involve ignition, are much different than for methane, as will be discussed further below.

A key event in combustion modeling was the development of the kinetic mechanism for natural gas oxidation, GRI-Mech [54]. Specifically designed to describe methane and ethane combustion, and limited to high temperature phenomena including particularly flame propagation and shock tube ignition, this mechanism was a product of a team of kinetics experts and was supported by the Gas Research Institute, an organization created to support uses of natural gas. An essential feature of this mechanism, which is presented in a format 
compatible to Chemkin codes, was that it was freely available to anyone and that the developers has tested the mechanism more thoroughly than any mechanism in combustion history. It has since become very widely used and is now an "industry standard" for the research community. Of course, this mechanism has suffered, like others, by usage under conditions where it has not been tested and was never intended to be used, such as very high pressures or temperatures below about $1000 \mathrm{~K}$, where additional mechanistic steps have to be added to treat production and subsequent reactions of $\mathrm{CH}_{3} \mathrm{O}_{2}$ and $\mathrm{C}_{2} \mathrm{H}_{5} \mathrm{O}_{2}$. But even when such minor modifications have been necessary [e.g., 55], GRI-Mech has been an enormous success and a positive addition to the computational modeling tools available to researchers. The development of GRIMech, the contribution of so many people to its creation and validation, and perhaps most important, the fact that it has been made available to anyone without cost, has been part of a larger trend that has helped make a single research community of combustion modelers worldwide.

\section{Growth of Kinetic Mechanisms}

Based on the hierarchical principles for kinetic mechanisms and the rapid growth in computer capabilities, development of steadily larger hydrocarbon fuel kinetic models followed those of methane and methanol, with ethene [56], ethane [57] and propane [58]. Warnatz [59] used these fuels to advance simulation of laminar premixed flames and the effects of difference in fuel composition on flame properties. 
Continued extension of kinetic modeling to hydrocarbon fuels of increasing size, led to kinetic mechanisms of even greater size. While early methane kinetic models included fewer than 20 chemical species, later models for propane and n-butane [60] reached about 100 chemical species, and later models for isomers of heptane and octane reached about 1000 chemical species [61].

Kinetic models require reaction rate, thermochemical and transport data for the rapidly growing number of species and reactions present, many of which have never been studied experimentally. Theoretical methods for calculating reaction pathways and rates of reaction have been developed [62], many of which now require supercomputer resources themselved to solve the complex quantum mechanical systems involved. Estimation techniques for reaction rates and thermochemical quantities required by models but without available experimental data have also been developed, such as the THERM code of Ritter and Bozzelli [63], based on Benson's principles of bond additivity [64]. Many detailed reviews of chemical kinetic and thermochemical data for wide ranges of hydrocarbon and other species have appeared in recent years [e.g., 65].

\section{Chain branching and sensitivity analysis}

Chemical kinetic reaction mechanisms are examples of the familiar concept of a chain reaction [66], with the radical species as chain carriers. Although mechanisms for some hydrocarbons now include thousands of elementary reactions, careful analyses of sensitivities to kinetic parameters consistently show that combustion rates are usually dependent on only a small subset of the many parameters in the kinetic model. These sensitivities are due 
to the roles, directly or indirectly, each reaction plays in contributing to the chain branching behavior of the reaction mechanism.

At high temperatures (above about 1100K) encountered in propagating flames, shock tube ignition, detonations, and pulse combustors, the primary chain branching is due to the single reaction

$$
\mathrm{H}+\mathrm{O}_{2}=\mathrm{O}+\mathrm{OH}
$$

which consumes one $\mathrm{H}$ atom radical and produces two new radicals, the $\mathrm{O}$ atom and the $\mathrm{OH}$ radical. Kinetic processes that increase the $\mathrm{H}$ atom population therefore will increase the rate of chain branching because those $\mathrm{H}$ atoms can react with $\mathrm{O}_{2}$ through $\mathrm{R} 1$, resulting in more rapid overall reaction. Kinetic processes that reduce the amounts of $\mathrm{H}$ atoms will correspondingly lower the over all rate of reaction because the chain branching rate is reduced. The rate of reaction $\mathrm{R} 1$ is therefore found to be the most sensitive reaction in models of laminar flames [e.g., 59,67] and other high temperature systems. The second most sensitive reaction in high temperature combustion models $[59,67]$ is

$$
\mathrm{CO}+\mathrm{OH}=\mathrm{H}+\mathrm{CO}_{2}
$$

which not only produces $\mathrm{H}$ atoms to react via R1, but also produces significant amounts of heat release through production of $\mathrm{CO}_{2}$. Different fuels and classes of hydrocarbons react at different rates in the high temperature range because of their rates of production of $\mathrm{H}$ atoms and subsequent different rates of chain branching. This produces different laminar burning velocity [59], shock tube ignition delay [e.g., 68] and detonation properties such as cell size and initiation energy [69]. 
This simple picture of hydrocarbon combustion sensitivity makes it possible to explain many additional problems in flame and ignition applications. Kinetic flame inhibitors such as $\mathrm{HBr}[70], \mathrm{CF}_{3} \mathrm{Br}$ [71], and organophosphorus compounds (OPC) [72] convert $\mathrm{H}$ atoms and other radicals into more stable compounds such as $\mathrm{H}_{2} \mathrm{O}$ and $\mathrm{H}_{2}$, thus reducing the number of $\mathrm{H}$ atoms that react via R1. A second example is the enhancement of ignition of methane in natural gas mixtures by increasing the percentage of ethane compared to methane in the natural gas. Other more subtle effects, such as the inhibiting effect of increased pressure on laminar burning velocity [67] or the influence of molecular structure on variable ignition rates of heptane isomers [68] are also attributable to the same reaction R1.

\section{Negative temperature coefficient and cool flames}

At lower temperatures, below about $1000 \mathrm{~K}$, low concentrations of $\mathrm{H}$ atoms and the relatively high activation energy of reaction $\mathrm{R} 1$ make it ineffective at producing chain branching. Instead, a rather involved series of reactions involving addition of molecular oxygen to alkyl and alkylperoxy radicals, intramolecular $\mathrm{H}$ atom transfers, and cyclization and decomposition reactions combine to provide significant levels of chain branching over a temperature range of about $600 \mathrm{~K}$ to $850 \mathrm{~K}$. In this region, the characteristic kinetic processes, commonly summarized as alkylperoxy radical isomerization [73] kinetics, proceed at overall rates that depend quite strongly on the size and structure of the hydrocarbon fuel involved [74]. The reaction sequence is initiated by addition reactions of alkyl and alkylperoxy radicals with O2. However, as the 
temperature increases above about $800 \mathrm{~K}$, the addition reactions, with rather high activation energies of about $40 \mathrm{kcal} / \mathrm{mol}$, begin to turn around and decompose back to radicals and $\mathrm{O} 2$, abruptly halting the chain branching reactions and slowing the overall rate of reaction. Thus there is a range of temperatures between $800 \mathrm{~K}$, where the low temperature chain branching sequence quits, and about $1000 \mathrm{~K}$ where the high temperature chain branching reaction $\mathrm{R} 1$ begins to become important, where the overall rate of alkane species oxidation is considerably reduced. The temperature range of this somewhat counterintuitive behavior is the called the region of negative temperature coefficient (NTC) and had been observed experimentally for many years. However, this phenomenon could not be explained satisfactorily until kinetic modeling was used to simulate the process. Extension of this type of kinetic analysis led eventually to a thorough description of the kinetics of engine knock, octane number, and HCCI ignition.

\section{Laminar flame modeling}

\section{Laminar premixed flame modeling}

The basic problem of laminar flame structure and propagation was nicely stated by Spalding and Stephenson [75]:

"(Laminar flame modeling) concerns the steady propagation of a plane laminar flame through a uniform mixture of (reactant) gases. The problem is: from supposedly known data for the chemical kinetic, transport and thermodynamic properties of the mixture, to compute the propagation speed, and the distributions through the flame of concentrations, temperatures, and reaction rates." 
Although this statement was made for the premixed formulation, the same can be said of the non-premixed case as well. This deceptively simple problem provides the foundation of a huge body of combustion phenomena, and it is an important problem to compute properly and accurately. This problem includes fluid mechanics, chemical kinetics, thermochemistry, mixing of fuel and oxidizer (for the non-premixed case), species and thermal diffusion, and it almost always exhibits two types of stiffness, first involving disparate time scales in the kinetics and also wide ranges in required spatial resolution. Therefore the laminar flat flame is a stringent test of a reactive flow model.

The laminar one-dimensional flame appears in many practical scenarios. In turbulent combustion, some regimes can be considered locally as laminar flamelets at sufficiently fine resolution. In thermal boundary layers, the flow near the boundary usually becomes laminar, and the ability to model laminar flame propagation enables one to study wall heat losses and problems in flame quenching. In fact, the laminar flame occurs constantly in many types of combustion in engines and other practical combustion environments. The laminar flame is also used frequently as a controlled environment in which to study many combustion phenomena including chemical kinetics, flame inhibition and quenching, limits of flammability, pollutant formation and destruction, and many others.

The equations for unsteady flame propagation were developed in virtually complete generality by Hirschfelder and Curtiss [76,77] around 1950. By about 1962, most of the underlying science had been developed to calculate flame structure and propagation, except for the computer hardware and the numerical algorithms needed to solve the equations. Libraries and methods of 
computing thermal conductivities [78], mixture thermal conductivities [79], specific heats and enthalpies [80], and viscosity and Lennard-Jones parameters [81] had all been developed.

Early attempts at computation of a laminar flat flame made extensive simplifications and solved the equations in the form of a two-pint boundary value problem [e.g.,77]. In the following years, many individuals made progress in flame modeling, as discussed by Spalding and Stephenson [75]. Most of these studies used ozone, hydrazine or hydrogen/bromine as the reactants, since their chemical kinetic mechanisms were very simple and the kinetic stiffness problem was not especially severe. An important issue was whether the steady-state, freely propagating laminar premixed flame should be simulated as a closed, boundary value problem or as the long-time solution of a transient problem. Although Spalding reported early in this debate [41] that the transient problem was far easier to solve using parabolic methods, most other modeling continued to use elliptic, closed solution methods. As late as 1979, Dixon-Lewis in his elegant paper on laminar flames in premixed hydrogen-oxygen-nitrogen [82] continued to use the boundary value formulation.

The other major issue in laminar flame modeling during this period concerned methods of dealing with stiffness. The first generation of fuels were so simple that little stiffness was encountered, but as soon as hydrogen flames were addressed, stiffness became a problem. A number of exotic accommodations to stiffness were tried, most of which appear curious or mysterious today. Dixon-Lewis $[82,83]$ had to assume either steady-state concentrations of the radical species in the flame, or partial equilibrium between those radicals, in order to retain stability of the solutions. Spalding and 
Stephenson [75] had to solve for the updated species concentrations in a particular order in the $\mathrm{H}_{2} / \mathrm{Br}_{2}$ flame (Br first, then $\mathrm{H}, \mathrm{H}_{2}, \mathrm{Br}_{2}$ and $\mathrm{T}$, with $\mathrm{HBr}$ concentrations solved by requiring the mole fractions sum to unity. This order can be understood a posteriori by reference to stiff equation methods developed at later dates. Dixon-Lewis [82] realized that the need for all of these tricks could be avoided by using the recently introduced fully implicit solution methods (see above discussion of stiff equation solvers for additional detail).

The period from 1970 through about 1980 was a transitional phase for computational combustion in general and for laminar flame modeling in particular. This is another illustration of the way that the laminar premixed flame problem often served as a representative problem for all of combustion research; that is, the premixed laminar flame is used to develop techniques that are then applied to other, more conceptally complex applications. The work of Spalding and collaborators was important because, while very simple kinetic models for ozone and hydrazine were treated, complexity in the form of realistic thermodynamic and transport data for multicomponent gas mixtures was treated, and the choice of solving this problem as a long-time solution of the transient problem, rather than the more difficult two-point boundary value problem, was established. In addition, other important concepts were first introduced, including the use of non-uniform grid spacing, putting grid points in greater density where most of the "action" was happening. Interestingly, in their 1971 paper, Spalding and Stephenson [75] introduced numerical algorithms for both freely propagating and burner-stabilized premixed laminar flames as special cases of the general problem. 
The work of Dixon-Lewis $[82,83]$ was important because, in spite of a solution algorithm that would eventually be discarded as overly complex and eventually unstable, concepts such as radical overshoot in the flame region were discovered. In addition, these papers identified the need for implicit numerical methods in solving the flame equations and examined the influence of parameters such as kinetic rate expressions, transport coefficients, unburned gas temperature, pressure, and composition for the first time. Together with the concurrent development of stiff equation solution techniques described above, by about 1980 most of the required computational science was available to support the modeling advances of the next 20 years, and nearly all of them were developed within the framework of laminar flame simulations.

Once these tools were in place, the next series of advances came rapidly. Warnatz carried out a series of landmark modeling studies for ozone, hydrogen and hydrocarbon laminar flames $[84,85,59]$ earning the Silver Medal at the 18th Combustion Symposium. A special issue of Combustion Science and Technology [86] examined a wide range of problems in modeling of laminar premixed flame modeling.

The next major event, one of the most significant developments in all of combustion modeling because it made reactive flow simulation available to everyone, was the introduction in 1980 of the Chemkin family of combustion models from Sandia National Laboratories in Livermore [87]. Over the next ten years, the PREMIX code, which solves the laminar premixed flat flame problem, the AURORA code, which solves the perfectly stirred reactor problem, the CRESLAF code, which solves channel flow problems, the OPPDIF code, which solves the opposed flow diffusion flame problem, PLUG, which solves plug flow 
problems, SHOCK, which solves incident and reflected shock tube prolems, Surface Chemkin, which solves surface chemistry problems with accompanying reactive gas mixtures, and other applications have been and continue to be produced. In addition to convenient availability, Chemkin established industry standards for computational combustion, with common solution techniques, common formats for problem formulation, and a common language for intercommunication of databases and problem results. The unifying role of Chemkin has not only been an outstanding technical contribution to computational combustion, it has also had an enormous social impact on this field. This made it possible for students and active professionals to communicate more conveniently, but also for them to be able to visit almost any other research facility in the world and be technically productive within minutes of arrival. This is not to say that the Chemkin code modules represent the state of the art in modeling of any of the systems they describe. Alternative codes are in use in many places for all of the functionality provided by Chemkin, and they are sometimes comparable or even superior in their performance on specific types of problems, but even those models have to be able to exchange input in "Chemkin format" so that others can compare mechanisms and results efficiently. Modernization of the Chemkin libraries and applications modules to modern computer languages and massively parallel computer architectures should be a priority in the near future. Although once available free of charge, the availability of the Chemkin codes has changed somewhat since they have been turned over to a private company, Reaction Design [88]. Over the past few years, a new publicly available, free to the user, code system called Cantera has been 
developed by Goodwin [89] which may replace some of the functionality of Chemkin at the "right price" for students and others with limited resources.

\section{Current capabilities}

\section{Surface Combustion}

Surface reactions play an important part in many combustion applications, including wall recombination processes during autoignition, coal combustion, soot formation and oxidation, and catalytic combustion. Furthermore, surface reactions play a key role in industrial catalysis, exhaust gas catalysis, and CVD (e.g., diamond, $\mathrm{SiC}$, carbon nanotubes etc.). About $80 \%$ of all chemical products are confronted with surface reaction during some stage of their production.

Heterogeneous reaction is the result of an interaction of diffusion processes from and to the gas phase, of adsorption and desorption processes on the surface, and of surface reactions which can occur between adsorbed species (“Langmuir-Hinshelwood mechanism”) or between adsorbed species and gas phase species (“Eley-Rideal mechanism”). Depending on the conditions, each of these processes can be rate-limiting and thus lead to a completely different behaviour of the global surface reaction. Sensitivity analysis in simple reaction systems shows that mainly adsorption/ desorption processes are ratedetermining, but it is forseeable that in more complex systems competing surface reactions, will lead to large sensitivities with respect to surface reactions, as well.

The main property for the quantitative treatment of reactions on surfaces (in comparison to gas-phase reactions) is the inclusion of surface sites and species adsorbed on these sites into the description of reaction rates. Surface sites and 
surface species (species that are attached to the surface site) have a surface concentration measured, e. g., in $\mathrm{mol} / \mathrm{cm}^{2}$. These surface concentrations in turn lead to initially unfamiliar units for reaction rates and rate coefficients. There may be more than one rate coefficient for the same material, since surface sites with different adsorption energies (e. g., on terraces and at steps [90]) or different geometric properties (e. g., in diamond growth [91]) have to be treated as different species.

Reviews of heterogeneous reactions are presented by Bond [92] and Christmann [93]. For numerical calculations, a general formalism for the treatment of heterogeneous reaction and details of the chemical reaction-rate formulation can be found in the users manuals for the SURFACE CHEMKIN [94] software, together with a review of basic phenomena. Advances in surface combustion and computational tools to describe the important processes have paralleled developments in silicon and diamond CVD, and many of the same researchers have worked on all of these systems (e.g., Coltrin, Kee, Frenklach).

Considering the success of the concept of elementary reactions in the quantitative understanding of gas-phase combustion, it was obvious at the begin of the 1990's to treat surface reaction in a similar manner and to start with surface combustion processes on noble metals, which are known to be effective oxidation catalysts. Some measurements on the oxidation of hydrogen [95-98] and simple hydrocarbons [99] on noble metal surfaces were available for comparison. Additionally, a lot of kinetic data were hidden in the literature, because of the use of different terms used in surface science [100]. 
Some early papers combined detailed surface and gas-phase reaction mechanisms for the hydrogen oxidation [100,101], while Ikeda et al. [102] and Williams et al. [98] simplified either the gas-phase or the surface kinetics. It was determined that $\mathrm{H}_{2}$ oxidation on $\mathrm{Pt}$ surfaces consists of dissociative adsorption of both $\mathrm{H}_{2}$ and $\mathrm{O}_{2}$, which leads to $\mathrm{H}$ atoms and $\mathrm{O}$ atoms adsorbed on the surface. These adsorbed atoms collide while attached to the surface, forming first $\mathrm{OH}$ and then adsorbed $\mathrm{H}_{2} \mathrm{O}$ in surface reactions, followed finally by desorption of $\mathrm{H}_{2} \mathrm{O}$ into the gas phase (see Figure 2).

Similar mechanisms exist now for the oxidation of $\mathrm{CH}_{4}$ [103]. It can be seen that knowledge of the detailed surface reaction mechanism is enabling us to understand partial oxidation processes as well, which play an important role in chemical engineering. Consequently, a lot of literature has been accumulated on this topic in recent years; see e. g., [104-106]. Furthermore, the treatment of threeway exhaust-gas catalysis [107-109] is possible with similar surface reaction mechanisms, as well as processes in high temperature fuel cells [110]. For several reasons, there is an urgent need for data on surface reactions. :

- Experimental rate data on many surface reactions are missing, which fortunately is often compensated by the fact that the adsorption/ desorption reactions are rate-limiting, not the surface processes [111].

- Complications are caused by the fact that surface species are not uniformly distributed, as gas-phase particles can be assumed to be. Instead, nonuniform surface concentrations can coexist, leading to phenomena like island formation and oscillating structures [112,113]. 


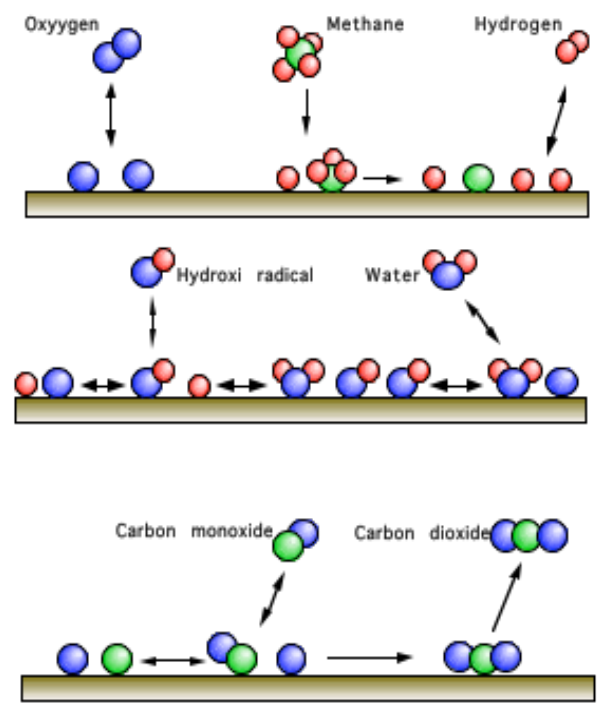

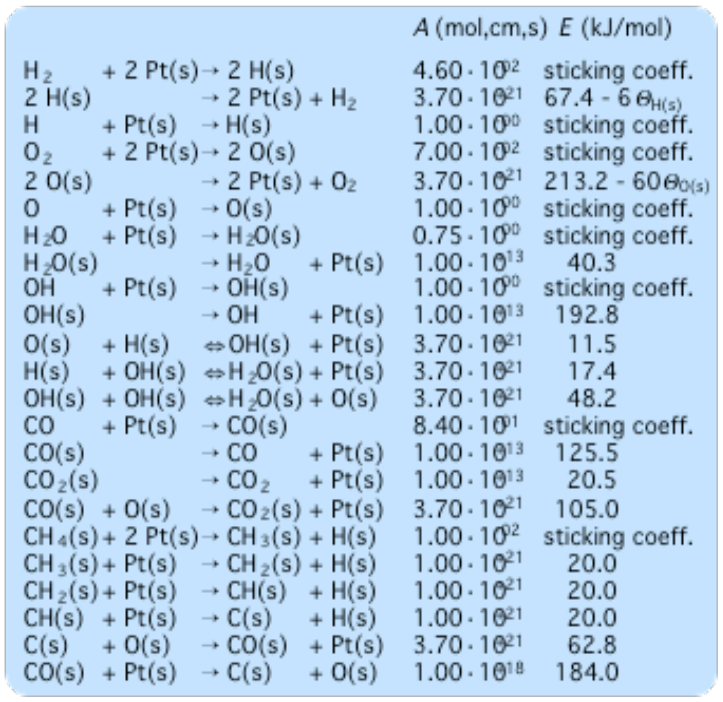

Fig. 2 Surface reaction mechanism of methane oxidation (schematic).

- Catalytic processes transition from kinetically controlled behavior at low temperature (indicated by a high surface concentration and a low gas-phase gradient in the boundary layer) to transport control at high temperature (indicated by a low surface concentration and a high gas-phase gradient). Thus, kinetic data are often hidden by transport limitations. 
- Hydrocarbon (partial) oxidation is complicated by the fact that hydrocarbon adsorption and surface decomposition mechanisms are unknown, because surface spectroscopy for intermediates is not yet sufficiently developed.

Therefore, limiting expressions for rate coefficients are frequently extremely helpful, even if they give only rough estimates [114], since understanding of surface reactions is far behind that of gas-phase reactions. Adsorption rates are usually assumed to be equal to the rate of gas-phase molecule collisions with a surface, multiplied by an empirical sticking coefficient. Surface reaction is modeled by assuming the surface atoms (or molecules) as a two-dimensional gas which than can be described by the simple formalism developed for gas kinetics. Desorption can be described by an Arrhenius-like expression with an activation energy that is comparable to bond strength between the desorbing species and the surface, and a pre-exponential factor estimated from vibrational frequencies of the corresponding bond.

However, recent advances in the development of surface species diagnostics like SFG (sum frequency generation) and SHG (second harmonic generation) indicate that this unsatisfactory situation of nearly complete lack of data for hydrocarbon oxidation surface reactions is improving [115-117]. 


\section{Current capabilities}

\section{Solid Fuel Rocket Motor}

Typical solid rocket motor propellants, such as those used in the Space Shuttle boosters, are composed of ammonium perchlorate (AP) and aluminum (Al) particles embedded in a fuel binder. A typical composition, by weight, is $71 \% \mathrm{AP}, 18 \% \mathrm{Al}$, and $11 \%$ binder. The aluminum reacts exothermically with $\mathrm{H}_{2} \mathrm{O}$ and $\mathrm{CO}_{2}$ in the chamber, increasing the specific impulse by about $10 \%$. It also provides efficient damping of chamber instabilities, a desirable effect. However, there are undesirable side effects such as slag accumulation, nozzle erosion, and smoke exhaust trails.

Traditional modeling efforts have forced the complex, inherently threedimensional combustion problem into an a priori one-dimensional model. Such a model neglects three-dimensional effects due to the non-planar surface regression, the propellant morphology, the gas-phase diffusion flames, and other factors, and as a result, the literature is rich with curve fitting approximations. Jackson and Buckmaster at the University of Illinois at Urbana-Champaign have developed a numerical framework which, for the first time, permits the exploration of detailed scientific issues in the combustion of heterogeneous propellants. The most important items of the framework are:

1. The modeling of propellant morphology: typical propellants consist of ammonium perchlorate (AP) particles embedded in a fuel binder, and well packed ( $\sim 80 \%$ by volume of AP). A packing algorithm was developed, treating the $\mathrm{AP}$ as spheres or discs, which enables one to generate packs which match the 
AP size distribution and packing fraction of industrial propellants $[118,119]$. A typical pack generated in this way is shown in Figure 3.

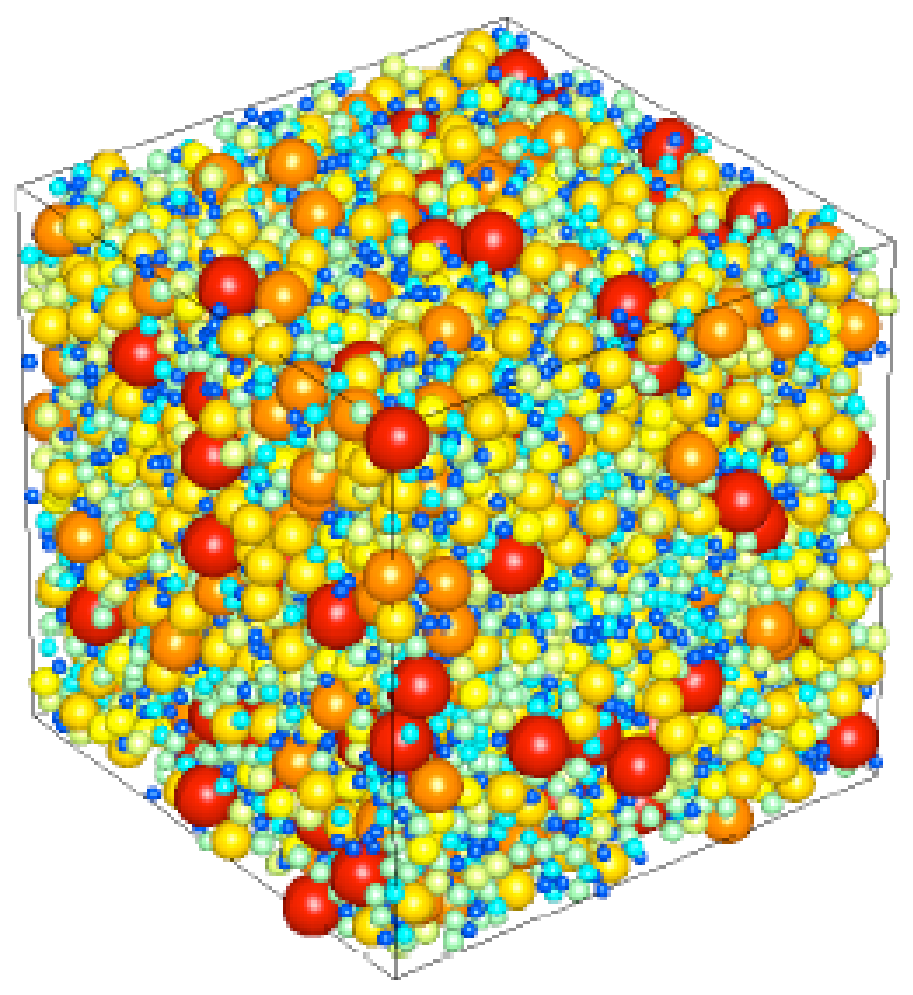

Fig 3: A typical randomly generated propellant pack. The red spheres are Al particles, the orange spheres are AP particles, and the small blue and green spheres are binder.

2. Homogenization: Industrial packs contain a large volume of fine AP, particles too small to be resolved numerically, and to account for them they are homogenized into the binder. When one does this, the properties of the blend in terms of the properties of the individual (AP, binder) components must be determined. Simple formulas for the heat conduction coefficient, and for the surface pyrolysis law, have been developed and numerically validated. These formulas are then used in the combustion simulations [120]. 
3. A phase-coupled unsteady 3-D combustion model: For the first time a propellant combustion model has been developed in which there is complete coupling between the gas phase and the solid phase, with an unsteady nonplanar interface separating the two. Moreover, this model accommodates the morphology modeling described above, and necessarily uses the homogenization formulas described above. The code is parallel, scalable, and has been run on a variety of massively parallel computers. A typical history is illustrated in Figure 4. For more details, see [121-124].

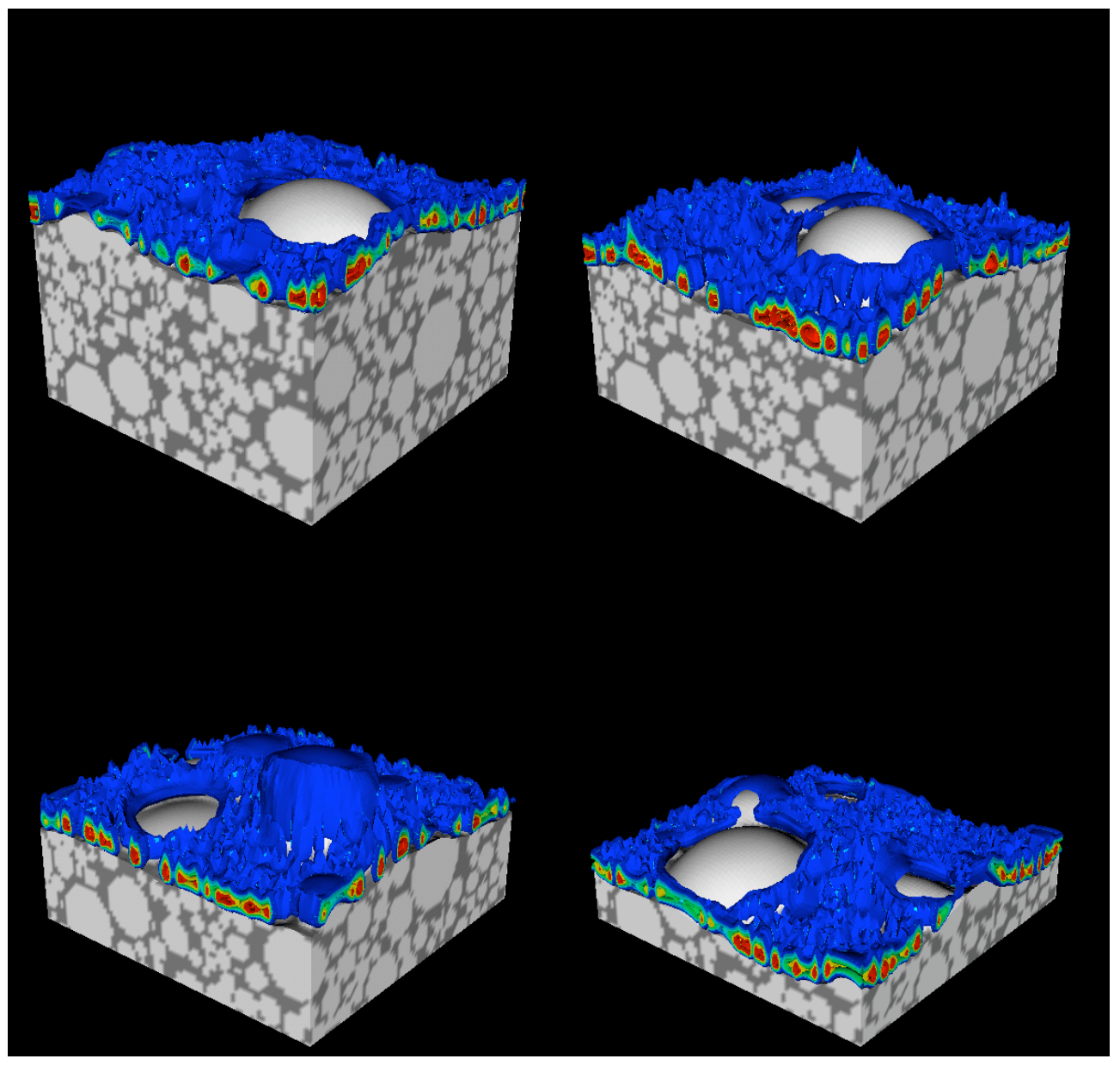

Fig. 4: Instantaneous total heat output generated from the three-dimensional combustion code. The surface regression and consumption of heterogeneous units in the propellant are evident. 
The numerical framework described above is currently being used to investigate a variety of important issues: the burning of non-spherical AP particles; proper LES boundary conditions; the acoustic response of heterogeneous propellant combustion [125]; extracting 1-D descriptions for coupling with large scale solid rocket motor simulations [126]; and ejection of aluminum from the burning surface into the chamber flow [127-129].

This massively parallel, 3D model of propellant burning describes a process which is itself only one of many submodels within a larger, massively parallel model of an entire solid fuel rocket motor. In addition to the propellant combustion, the material dynamics of the rocket case and the joints between case sections are simulated, flow through the exit nozzle is fully resolved, surface regression of the propellant is followed as the propellant burns, acoustic stability of the interior gas flow is examined, and accumulation of aluminum slag in the region near the exhaust nozzle and its effects of restricting exit flows are all included in the fully 3D model.

This modeling effort provides an excellent example of how both the overall model and some of the submodels can require massively parallel computing resources since the level of complexity in each part of the problem can be quite comparable. 


\section{Current capabilities}

\section{Pool fire in a crosswind}

The University of Utah has been carrying out simulations involving a fire of a large pool of hydrocarbon fuel. Heat from the resulting large pool fire could then damage or burn other objects. The critical submodel in this case is the hydrocarbon fuel pool fire, which is assumed to be the jet fuel JP-8, which is a kerosene-type fuel. This pool fire has been found to be an enormously complex combustion problem in itself, demanding a fully 3D formulation, detailed chemical kinetics and turbulent fluid mechanics with a potentially strong and time-dependent atmospheric cross wind. In addition, heat transfer to other objects depends strongly on radiation transport through a heavily sooting environment. These complications result in a requirement of massively parallel computing resources and the development of an extremely complex set of numerical methods, including new visualization tools.

The present pool fire model has required computational combustion research in several areas. Since JP-8 is one of a class of complex hydrocarbon mixtures that are difficult to characterize or model, a surrogate kinetic reaction mechanism has been developed for it [130], including components iso-octane, methyl-cyclohexane, toluene, $\mathrm{n}$-decane, $\mathrm{n}$-dodecane, tetradecane and tetralin. In addition to reproducing the ignition and flame of the jet fuel, the surrogate was selected to also reproduce the volatility, sooting tendency and boiling-point curve of the actual practical fuel, JP-8.

The resulting model simulation, computing in a stand-alone mode without side winds, is shown in Fig. 5, and shows the "puffing" behavior common to such pool fires. In the figure, one puff has risen well above the pool, 
while the next puff is just forming at the base of the pool fire. The timedependent model is able to predict the frequency dependence of puffing as a function of pool diameter, and the computational model can be used to examine many other features of these flames. Additional studies of the same pool fire with a wind incident from the side shows how stretch and buoyancy interact, the the resulting rates of heat transfer to peripheral objects is important to the business of fire safety. The early growth of this flame is shown in four frames in Figure 6. Each pool fire simulation is a massively parallel computing problem, and the total system with all of its complex features including the structures affected by the pool fire will still require more computer capabilities than those existing today.

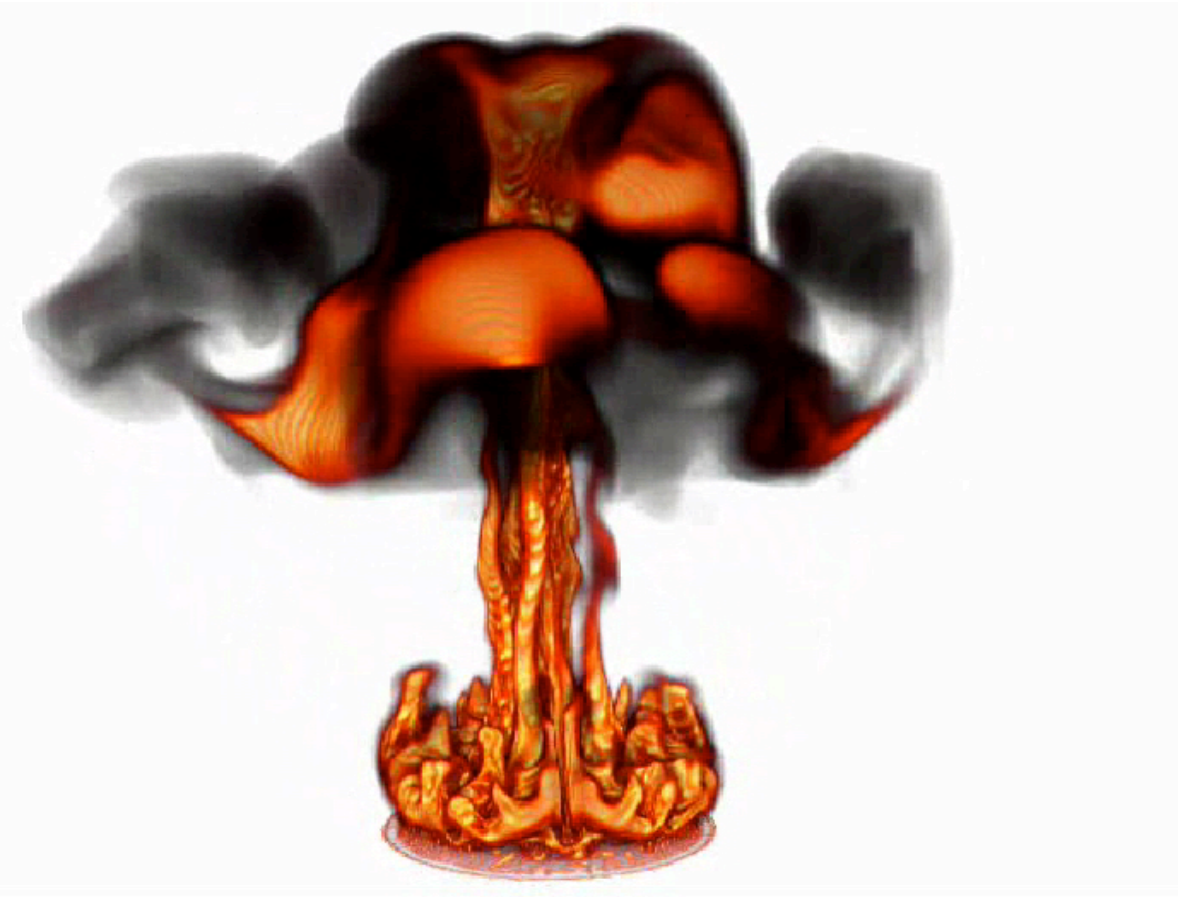

Figure 5. Pool fire without crosswind. The upper portion is the first "puff" and the second puff is just forming. 

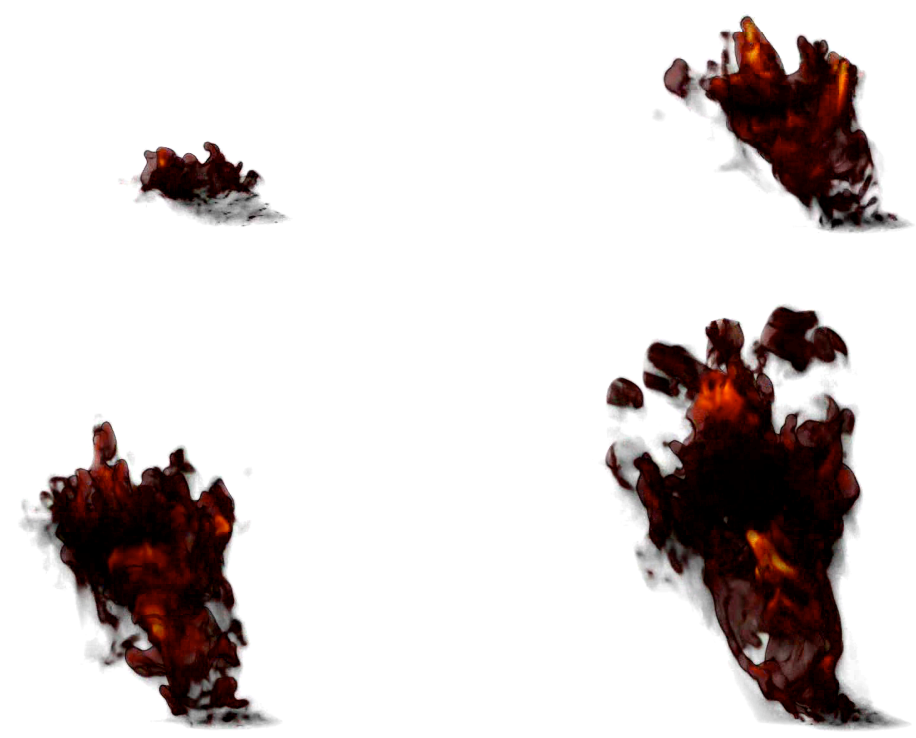

Fig. 6. Growth of a pool fire in a cross wind 


\section{Shock Tube Ignition}

Shock tube ignition of various fuel-oxidizer-diluent mixtures has long provided essential data used for development and validation of kinetic reaction mechanisms. Years ago, the main product of a shock tube ignition study was an overall correlation between initial reactant concentrations and temperature with ignition delay. However, as kinetic models have become more sophisticated and general, these data are invaluable as tests for kinetic models. A particularly good example of this is the study by Burcat et al. [131], who studied the ignition of a family of paraffinic fuels from methane to n-pentane in mixtures of oxygen and argon. This provides a sort of "longitudinal" comparison of fuels whose structure (i.e., n-alkane) is the same, but the length of the straight chain is increasing. This set of shock tube experiments has been very useful in testing kinetic reaction mechanisms [132]. The companion strategy is to compare the ignition of a family of fuels with the same composition but different structures, which occurs for the structural isomers of a fuel such as heptane [68]. This type of experimental study makes it possible to study the influence of either fuel size or molecular structure on combustion properties. Another set of shock tube experiments by Adomeit and colleagues $[133,134]$ at lower temperatures have been extremely valuable in testing kinetic models $[135,136]$ at low temperatures and high pressures, making them relevant to kinetic models of diesel and HCCI ignition. An excellent review paper summarizing a great deal of shock tube literature has appeared recently [137]. 


\section{Detonations}

A detonation is a chemically reactive shock wave, in which the shock wave compresses and heats a reactive mixture and initiates reaction. There is an enormous literature on detonation chemistry and physics, but chemical kinetic modeling has provided some unique insights into detonation processes. Reactive shock waves decay in strength, and reignition of the fuel/air mixture is necessary to re-establish the reactive shock wave. The most fundamental experimental study of detonation phenomena was published as a Silver Medal paper at the 17th Combustion Symposium by Matsui and Lee [138], and the corresponding kinetic modeling work [139] provided a chemical kinetic basis for those experimental results. Subsequent studies $[140,141]$ have further extended the value of the coupled experimental/ kinetic modeling analyses of these systems, showing how additives and pretreatments can change detonation properties.

However, the most significant numerical modeling analyses of detonation science have been done by Oran and colleagues [142,143], which have included full fluid mechanical descriptions of the shock wave propagation, with submodels incorporating the fully detailed chemical kinetics in table lookup format. These have been enormously productive model simulations; since they have been reviewed recently and expertly, we will not repeat that here.

\section{Pulse combustion}

In the pulse combustor, after each ignition the combustion is quenched by exhaust flow out through the tailpipe. Fresh fuel and air is introduced into the combustion chamber due to the decrease in combustion chamber pressure, and 
after a suitable ignition delay, combustion is again initiated. The same high temperature hydrocarbon ignition kinetics as that involved in the shock tube and detonations control this ignition, but there is a new feature in this system. The key to this system is not to ignite the fuel/air system as rapidly as possible, as in the reactive shock in a detonation, but to ignite that mixture so that it ignites in phase with the sinusoidal pressure waves in the combustion chamber, a principle known as Rayleigh's Criterion. Therefore it is sometimes beneficial to retard the ignition to improve combustion performance. Kinetic modeling of pulse combustion, supporting the experimental studies, produced a broad theoretical understanding of these systems [144-147]. In particular, the modeling analysis showed how fuel composition could be varied to optimize (i.e., "tune") the performance of the pulse combustion system. 


\section{Current capabilities}

\section{Internal Combustion Engines}

Computer simulation of a wide range of phenomena in internal combustion engines has been a particularly fertile research area over the past 30 years. Initially, it was possible to model either CFD simulations without combustion or any other physical or chemical subsystems, or simulations of a particular subsystem, due to limits in computing capacity. However, for a variety of reasons, extraordinary levels of resources and attention began to be focused on engine problems, beginning in the mid 1970's. The conditions were ripe for making rapid progress at this time; 2D CFD models had already appeared and applied to models of atmospheric problems and general circulation models (GCM's) [7], astrophysics [8], and plasma physics [9]. Computer power was increasing steadily, with CDC 6600 and 7600 computers providing sufficient capability to address significantly more ambitious problems than previous computers.

Interestingly, when changes in international politics led to steady reductions in funding for defense modeling applications, computational scientists at the three US weapons laboratories, Los Alamos, Lawrence Livermore and Sandia, with their unique computing capabilities and experience in using such tools, turned to combustion modeling in significant numbers. An initial handicap was the fact that few of these scientists and engineers were particularly knowledgeable in combustion science.

Two important events were particularly important. An influential

"Workshop on the Numerical Simulation of Combustion for Application to Spark and Compression Ignition Engines" was held [148] in 1975 with 
participation of a large majority of those people starting to develop engine combustion models, as well as enthusiastic involvement by modeling advocates from the auto industry. This workshop identified much of the work needed to enable computer modeling to address the current questions most important to engine combustion, simultaneously educating the modeling community and showing the industrial participants about current modeling capabilities.

Specific technical problems that emerged from this workshop included studies of laminar premixed and diffusion flames at elevated pressures, flame quenching on engine surfaces, burning of individual fuel droplets, soot kinetics, radiation transport in engines and furnaces, influences of fuel variability, effects of the complex composition of gasoline and diesel fuel, flows through intake and exhaust ports, turbulent coupling between fluid mechanics and chemical kinetics, and a realization that some problems could be addressed in homogeneous and one-dimensional geometry, while others would require 3D formulations. The unusual insight and leadership of Bracco at Princeton University and Hartley at Sandia then made an enormous impact on this problem, persuading the US government to support a number of collaborative research efforts to be carried out by mixed teams of people from the US defense labs, universities and the American auto companies General Motors, Ford and Chrysler. The outcome of the SAI workshop provided support material to convince government agencies that these collaborations were uniquely able to address these important problems and that funding them would be a good use of taxpayers' money. This approach led to outstanding results in many areas, including development of in-cylinder engine diagnostics and laser diagnostics in particular, and to important combustion models that have since permeated the 
combustion research community, including the KIVA and HCT [149]

multiphysics codes, the Chemkin codes, many important submodel simulation codes for chemical kinetics, advanced radiation transport, spray formation and evolution, wall heat transfer, ignition and many others, as well as a lengthy list of research publications in all of these subject areas. Perhaps even more important, this program connected industrial, university and national researchers and led to long-term productive collaborations, many of which endure today. It also created a culture of technology transfer, especially bringing modeling techniques into the industrial environment and rapidly establishing the credibility of such techniques and their usefulness in practical applications.

Initially, individual collaborations were established between General Motors Research, Princeton University, and SNL, LANL and LLNL, to study the general concept of direct injection, stratified charge, spark ignition engines, and between Ford, University, LANL and SNL to study lean burn, homogeneous charge spark ignition engines. Subsequent collaborative teams focused on engine knock in spark ignition engines, diesel engine soot emissions, and later on quite different industrial combustion areas such as pulse combustion and spray combustion. These teams still exist, currently focusing on diesel engine combustion and Homogeneous Charge Compression Ignition (HCCI) engines. Literally hundreds of publications were produced from these research and development teams.

This concept was esssentially repeated in Europe by the IDEA/JOULE program with the European Community, involving European auto manufacturers, universities and others from many countries, again with excellent results in many areas. The concept of industry/academic teams was a 
revolutionary change in the combustion research field and was of great importance to the development of combustion modeling. Some of the submodels highlighted in the present paper were key results of these collaborations.

\section{Spark-Ignition Engines}

Many of the models of SI engines evolved with the KIVA code as the organizing application. The earliest codes were primarily 2D in form, with simplified (usually single step) reaction submodels, "thin" spray evolution submodels, simplified wall heat loss models, no radiation submodel, and a k-ع turbulence model. Even with these limitations, the models were able to evaluate different formulations for stratified charge combustion and identify strategies that were likely to be successful and others that were likely to produce unacceptable emissions. In addition, 1D CFD models that included more complex submodels were successful in elucidating the nature of many practical problems.

For example, modeling with 1D geometry and detailed chemical kinetics was able to demonstrate [150] that the widely believed mechanism of flame quenching on engine chamber walls was probably not the major source of cylinder-out unburned hydrocarbon emissions from SI engines. The model calculations indicated that while the flame did approach the cold wall and come to a halt, unburned fuel in the trapped boundary layer diffused rapidly out into the hot region of the stagnated flame and were consumed rapidly. As a result, the fuel that has always been thought to be trapped in the thermal boundary layer and subsequently present in the exhaust, was actually consumed well in advance of the piston exhaust stroke. Previous model calculations for the same 
problem by Adamczyk et al. had arrived at a similar answer, but their model included only a global reaction for heat release, and the authors felt that such an important result could not be trusted without a much more accurate and detailed kinetic model. Another early model calculation, again with a simplified, twostep reaction mechanism [151], arrived at the same general conclusion. Subsequent experimental studies [152] confirmed the overall result, which overturned more than 50 years of "common knowledge" about hydrocarbon emissions. Since this work indicated that wall quenched flames were not likely to be the major source of unburned hydrocarbons from engines, researchers then turned their attention to alternative explanations for these emissions, soon finding them in piston ring crevices, oil layers, and other minor locations, summarized very well in SAE publications from Heywood and others at MIT [153]. Since wall quenching of flames involves heat transfer to those walls, the same type of modeling approach has been used extensively in studies of wall heat transfer [154], and additional modeling studies of flame quenching and heat transfer coupled to engine knock in SI engines have also been carried out [155].

Flame interaction with combustion chamber walls includes exchange of heat and chemical species with the wall, and it is of general importance for many combustion systems, as discussed previously. Heat transfer to walls can be a desirable result in cases where a working fluid is being heated or when heating the material is the goal such as in welding, when heat transfer from the wall to the reactive gas is used to ignite gas phase combustion, or heat transfer can quench flames in a near-wall region in a combustion chamber and lead to unburned hydrocarbon emissions. Exchange of chemical species between a flame and a surface occurs in catalytic combustion and is also the basis for CVD 
applications. Computer models of all these processes are essentially the same, using a gas phase model with CFD and chemical kinetics, a surface model describing the chemical nature of the surface and some way to account for surface coverage by different chemical species, and a chemical kinetic mechanism for the species on the surface which will certainly not be the same mechanism as that in the gas phase.

Flame/wall interactions are usually modeled in either the "head-on" geometry with the flame incident normally on the surface, or in tangential geometry with the flame propagation parallel to the wall. Both laminar and turbulent flames have been studied in both geometries, with some treatments assuming that even in turbulent environments, a laminar layer should be expected near the cold wall. There have been a large number of such computational studies [156-159], reflecting the importance of this single problem in combustion, although the "complete" computational problem, with turbulence, detailed chemical kinetics, and detailed surface chemistry has not yet been carried out.

In other similar engine studies, detailed chemical kinetic modeling confirmed experimental results and provided the fundamental understanding of the process; experiments by Lancaster [160] on early injection, stratified charge engines found large amounts of unburned hydrocarbons in the emissions, and subsequent flame modeling with detailed kinetics [161] showed that, in early injection cases, even where ideal charge stratification had been achieved, fuel diffusion during flame propagation moved considerable amounts of unburned fuel into regions in the combustion chamber where the equivalence ratio was too low to support a flame, resulting in very high levels of unburned hydrocarbons. 
This enhanced level of basic understanding then led to a new conceptual design, a late-injection stratified charge process where the modeling indicated a good likelihood of much lower hydrocarbon emission, which was confirmed in subsequent experiments. In another case, engine experiments by Quader [162] in lean, homogeneous SI combustion found unacceptably high unburned hydrocarbon emissions if spark timing was sufficiently retarded. Further experiments in a laboratory rapid compression environment, coupled to a flame model again with detailed chemical kinetics, demonstrated [163] that the mechanism for Quader's experiments was flame quenching due to adiabatic expansion and cooling of the reacting gases by the moving piston; under very late ignition and very lean conditions, further expansion of the combustion chamber reduced the temperature and radical concentrations in the flame, halting its progress and leaving all of the remaining fuel in the combustion chamber essentially unburned.

\section{Engine knock}

A major difficulty with SI engine combustion is that engine knock can occur as the compression ratio is increased. The thermodynamic efficiency of the engine increases with increasing compression ratio, so the onset of knocking limits operational efficiency. This problem was first identified during World War I when the role of airplanes in the war changed and required better engine power production, which was then limited by the onset of knock. As a result, in the years following World War I, extensive tests were carried out to determine the caused of knock. The role of hydrocarbon fuel molecule size and structure in determining knocking tendency became understood in phenomenological terms 
[164], and effective antiknock additives were discovered [165,166], although none of this work explained the fundamental causes for the observed behavior or for the effectiveness of the antiknock compounds. In recent years, detailed chemical kinetic modeling has been used [167] to develop a fundamental theory of how fuel size and structure influence knocking, as well as the methods by which antiknock additives such as tetraethyl lead (TEL) and methyl tert-butyl ether (MTBE) work in kinetic terms. In this analysis, which took place over nearly ten years, experimental studies in rapid compression machines [168,169], static and flow reactors [170], and motored engines [171-173] were used along with experience with operating engines to refine and test the predictive and interpretive capabilities of the kinetic models.

These kinetic models are continually being refined, and the needs of kinetic models for more demanding test data are motivating new experimental studies. For example, model predictions for ignition of isomers of heptane $[61,68]$ have led to experimental kinetic studies of oxidation and ignition of the same isomers in nonpremixed flames [174] and in rapid compression machines [175].

For example, experiments were carried out using a rapid compression machine with the 3 structural isomers of pentane as fuels. For these fuels, the knocking tendencies as measured by Research Octane Number (RON) were in the order n-C5H12 (RON=62), iso-C5H12 (86) and neo-C5H12 (92). In the RCM, these fuels ignite in the same order as their octane numbers, as shown in Fig. 7. However, similar correlations between RON and ignition in the RCM have been shown to be only approximately correct. For example, in RCM experiments with the 9 structurally isomers of heptane [175], n-heptane was shown to ignite most 
rapidly, and the singly branched methyl hexanes were next fastest to ignite, both trends in good agreement with values of RON. However, the 4 doubly-branched isomers (di-methyl pentanes), all of which have values of RON between 80 and 93, did not uniformly ignite in order of their RON values, although the general trends were observed to be in rough agreement. Computer modeling of the same ignitions of the heptane isomers [68] similarly showed minor inconsistencies between RON and ignition delay times in the RCM. These differences are not surprising, since the reacting gases in the RCM encounter a different time/temperature/pressure history than the end gases in a SI engine, so exact correlations should not realistically be expected. Much of this work reflects a goal of using computer-based models to provide guidance for fuel refinery and engine combustion processes.

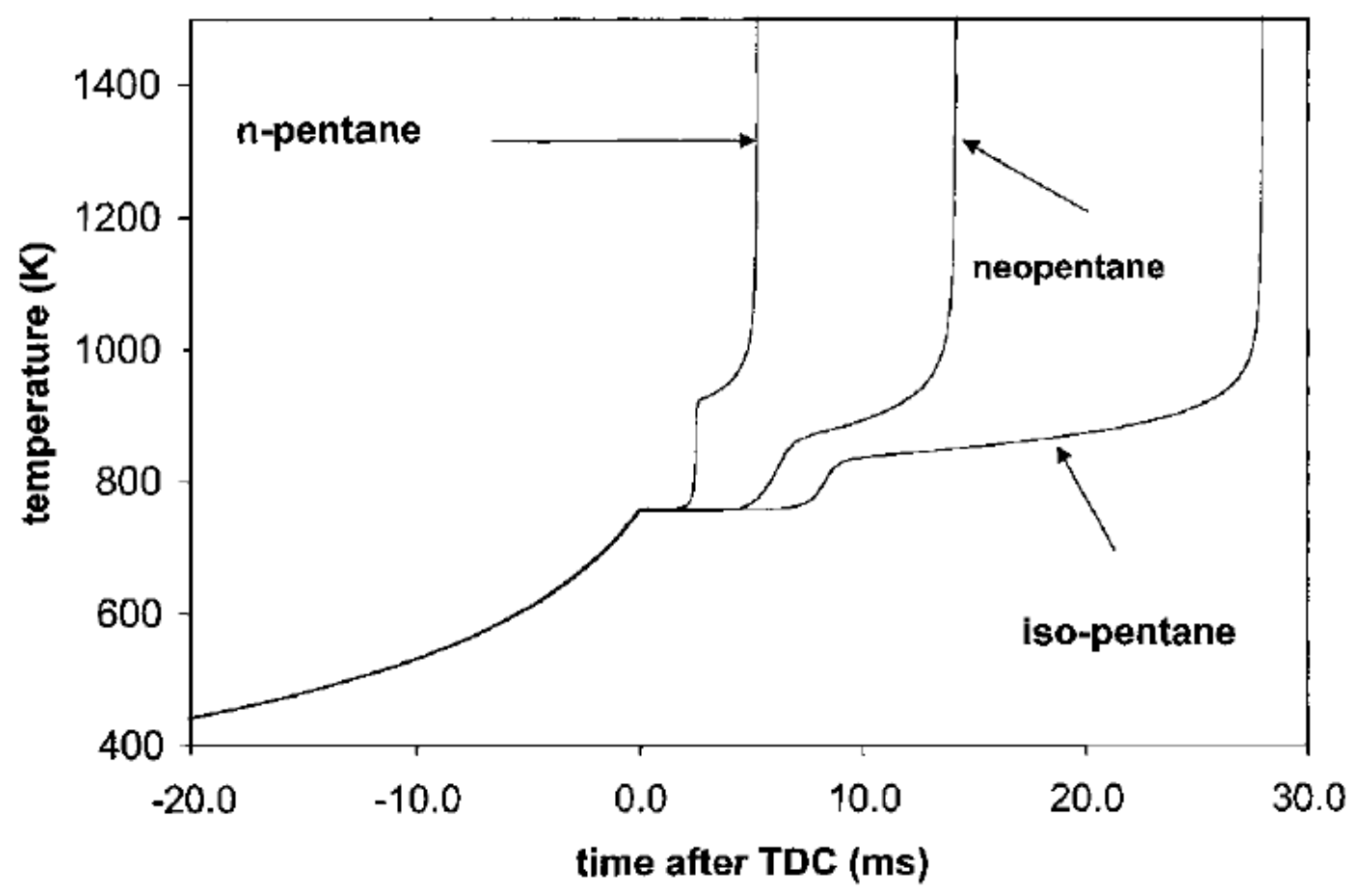

Figure 7. Ignition of three pentane isomers in a rapid compression machine, showing ignition occurring in order consistent with research octane number. 


\section{Fuel Sprays}

In direct injection spark ignition engines, as well as in diesel engines, the fuel is inject directly into the combustion chamber. The liquid fuel jet breaks up into droplets, which then break up further and evaporate, mixing with air and eventually being oxidized. There are quite a few steps in this process, each of which has been approached first by experiments and eventually via computational modeling. Overall, spray combustion is not as far advanced as some other simulations of practical combustion, but it is also a much more complex physical and chemical system than most, and considerable current work is occurring at each stage of this problem. Numerous excellent and thorough reviews of spray combustion have been published in recent years [176 and other previous reviews cited therein], and this brief summary will try only to summarize the current capabilities.

Spray combustion can be separated conceptually into (a) liquid jet penetration, (b) jet breakup into smaller, irregularly shaped pieces, (c) formation of droplets, (d) transport of droplets while they evaporate, collide, scatter, recombine, and slow down, and (e) reaction in the gas phase. The state of the air into which the spray is injected has profound implications on each of these steps, so spray models are intrinsically coupled to a CFD model. Perhaps the most important of these are the density of the air and its turbulent nature.

Early spray models started their simulations at stage (d), assuming an initial distribution of droplets in size, velocity and occasionally in composition. Considerable effort was taken to make these distributions as correct as possible, usually by means of very difficult experiments to image the droplets in a 
transient flow system. The droplets then proceed in space in a ballistic fashion, slowing down due to aerodynamic drag, and evaporating as predicted by the Clausius-Clapeyron equation. This was the general approach used in early versions of the KIVA code [15], which eventually included other droplet dynamics effects including droplet collisions followed by changes in trajectory and droplet coalescence to make larger droplets. Other later developments included deposition of energy and momentum, in addition to mass, into the gas phase via the drag terms.

This type of division into stages then accommodates many opportunities for adding refinements, and this is where the majority of the subdiscipline is currently working. A good example is the paper of Kim and Huh [177], who explain that they are assuming that the fuel enters the combustion chamber as droplets with assumed properties. They then use different evaporation submodels, different initial droplet fuel temperatures and size distributions, spray angle and total volume of fuel injected. They use a particular model, the Conditional Moment Closure (CMC) model [178] and a single detailed chemical kinetic reaction model for the $\mathrm{n}$-heptane fuel. The kinetic equations are solved using Chemkin.

Another model by Dryer et al. [179] treats only a single droplet in an infinite air volume, and the focus is on the effects associated when the droplet consists of a 2-component mixture, methanol and water in their case. They solve the detailed multicomponent diffusion equations in the gas phase, evaporate the two components at different rates, and solve the detailed chemical kinetic rate equations for methanol in air. Much of this work $[179,180]$ utilizes data from 
spray experiments in drop towers, which removes buoyancy-induced deviations from spherical symmetry

As described by Faeth [176], different modeling efforts approach each of the stages outlined above in these problems. Current work is addressing such problems as liquid jet breakup from hydrodynamic instabilities, opposed flows of liquid jets, and variations in nozzle geometry. Once formed, differences in droplet evolution due to the presence of neighboring droplets and by gas and liquid phase turbulence, and supercritical and emulsion properties of droplets can make then explode or vaporize rapidly.

\section{Diesel engine modeling}

Experience with computational simulations of diesel combustion provides an interesting view of a relatively little-appreciated element in combustion modeling, specifically the role of a conceptual model for the overall combustion process. For example, in the early days of diesel combustion, it appeared that the fuel jet injection into the engine produced a fine mist of liquid fuel droplets which then ignited after a suitable time delay. Further fuel addition in spray form added new fuel which was believed to be ignited by the initial droplet flame. One major product of this process was soot, which was eventually consumed later in the engine cycle.

Unfortunately, detailed analysis of the elements of this overall process defied explanation. The initial ignition of the spray could never be reproduced by any first principles model, with computed ignition delay times often inconsistent with experimental results by orders of magnitude. Subsequent fuel consumption could not be linked computationally to the ignition, and soot 
production from this system was also difficult to simulate. In retrospect, it should have been apparent that the models were warning that the conceptual model of diesel combustion was fundamentally flawed.

A reliable conceptual model of diesel combustion was eventually developed by Dec and colleagues at Sandia/Livermore [181] on the basis of complex, multiple laser in-cylinder diagnostics, and the satisfying result of this extremely ambitious and demanding series of studies has been a formulation in which all of the elementary processes fit neatly together [182]. In this conceptual model, shown in Fig. 8, most or all of the fuel vaporization is complete prior to ignition. The vaporized fuel mixes with and entrains hot air, steadily reducing the local equivalence ratio and heating the fuel/air mixture. Ignition occurs for the same reason as in SI engine knock, that the reactive fuel/air mixture ignites

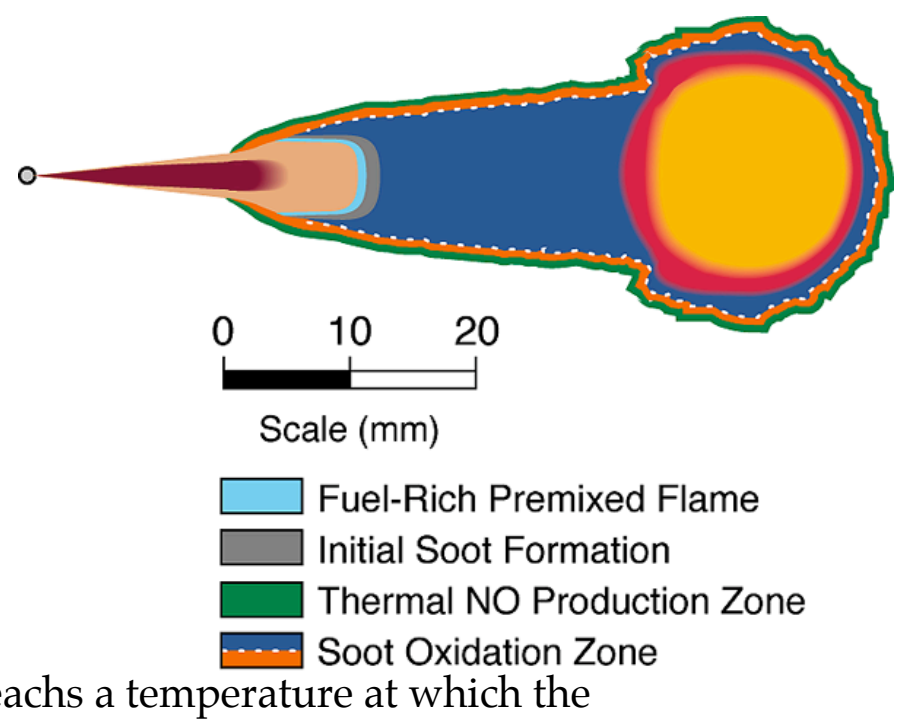

Figure 8. Conceptual model for diesel ignition and combustion based on laser diagnostics by Dec [181]. 
$\mathrm{H}_{2} \mathrm{O}_{2}$ decomposes. The time delay to ignition in the diesel is measured by the fuel cetane number, and the similarities in ignition kinetics mean that both octane number and cetane number are determined by the same kinetic pathways. The only real difference is that ignition in the diesel generally occurs at fuel-rich conditions $(\phi \sim 2)$ while engine knock occurs in mixtures that are lean or close to stoichiometric. Because the conditions are so rich in the diesel ignition, the reaction does not go to completion; kinetic model computations show [182] that large amounts of unsaturated, small hydrocarbon species are produced during this rich ignition, and most of the available oxygen leads to CO.

The work of soot chemistry researchers such as Frenklach [183] has shown that the major growth species that produce soot are small unsaturated species such as acetylene, the same species that are found in the products of this diesel rich, premixed ignition, so these products very naturally start making soot. The next region in Fig. 8 downstream of the ignition zone is identified as a soot production region, which was identified by Dec using laser-induced incandescence (LII) [181]. Very little oxygen is able to penetrate here, so soot growth is relatively unimpeded. Soot combustion occurs preferentially at the periphery of the soot cloud under conditions that are similar to those in a diffusion flame.

Each piece of this sequence has been studied using fluid mechanical and kinetic modeling as well as experiments, confirming the overall validity of the major steps. A number of different researchers [184] have used kinetic modeling to compute the ignition and formation of hydrocarbon fragments under rich 
conditions, which commonly reach a product temperature close to $1600 \mathrm{~K}$. This is then coupled to a soot production model from Frenklach [183] to predict the levels of soot produced from that initial mixture of fuel and air. This enables one to compare the relative sooting tendencies of different fuels or at different operating conditions. These studies have also indicated that, as far as ignition and soot-producing tendencies, n-heptane seems to be a serviceable surrogate for diesel fuel. A much more complete discussion of soot precursor formation and soot production can be found in another review in this same Symposium [31], and we will leave further details to that paper.

Another class of applications of the same approach have addressed the role that oxygen content in diesel fuel plays in reducing soot production. Recent experiments by Miyamoto et al. [185] have shown that when oxygenated hydrocarbon fuel components are added to diesel fuel, the levels of sooting are reduced, until the engine was found to produce no soot when the oxygen content in the total fuel reached about $25 \%$ of the total fuel. A variety of oxygenated species were used to dilute diesel fuel, and the general trend was the same for all of the oxygenated additives used. These experimental results are shown in the top portion of Fig. 9.

The same trends were reproduced numerically using a range of oxygenated species $[186,187]$. In the bottom portion of Fig. 9, the total concentration of known soot precursors, including acetylene, and vinyl and propargyl radicals are plotted as functions of increasing oxygen content in the diesel fuel, and it is clear that the same trend seen in the experimental data is reproduced in the computed model results. The spread in the computed results suggests that the MB (methyl butanoate, a type of simulant for biodiesel fuel) 
and DBM (dibutyl maleate) are somewhat less effective in reducing soot than the other oxygenated fuels, and the model shows that the details of the arrangement of the oxygen atoms in these 

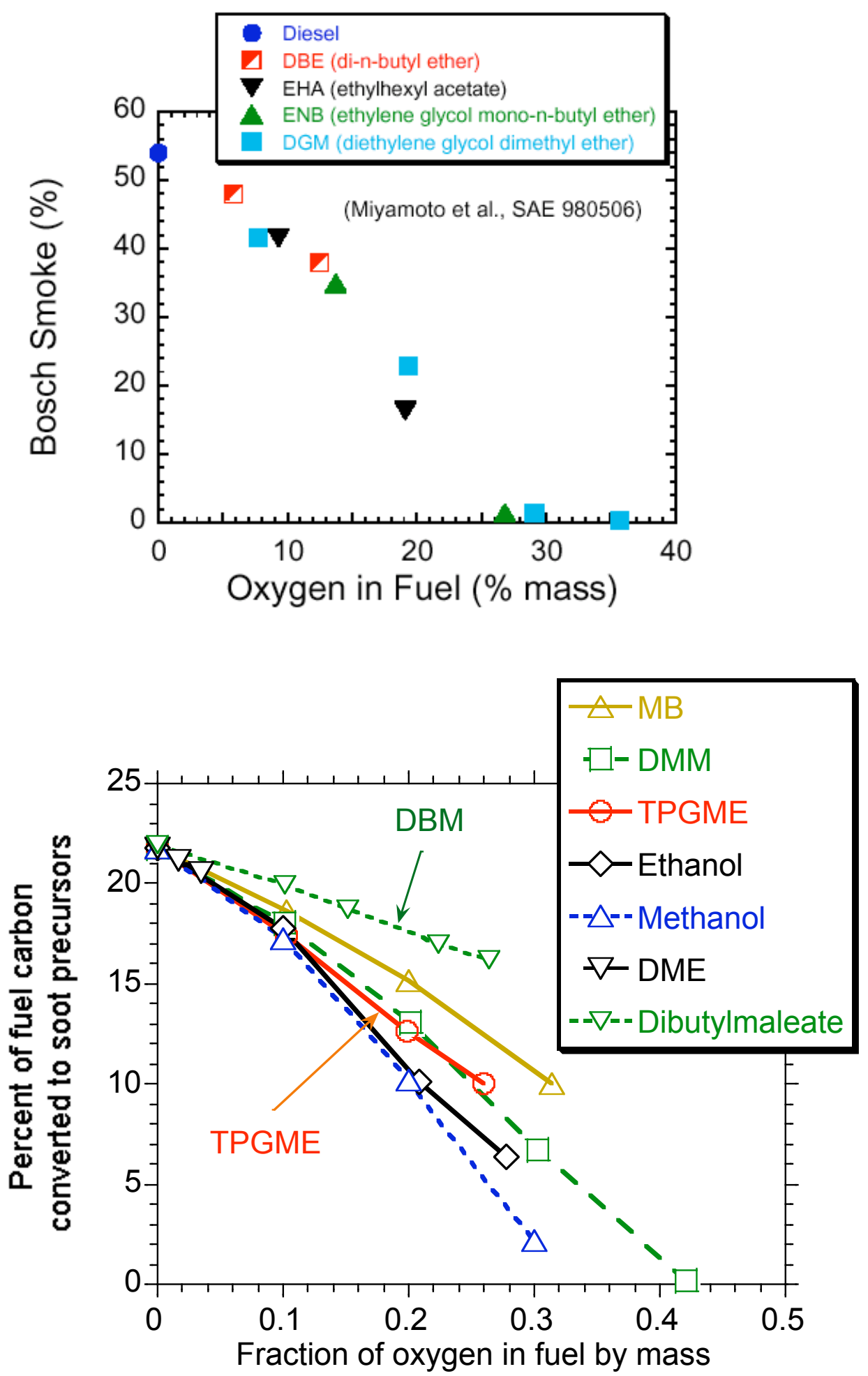

Fig. 9 (Top) Experimental diesel engine results [184] showing soot reductions as oxygen content of the fuel is increased by adding oxygenated hydrocarbons. (Bottom) Computed concentrations of soot precursors in products of rich ignition, n-heptane used as the representative diesel fuel, oxygenate additives as indicated in accompanying table. 
oxygenates is important in determining their role in soot suppression. The role of these oxygen atoms is to form $\mathrm{CO}$ bonds and thereby remove that $\mathrm{C}$ atom from the pool of potential soot-producing species. In DBM and MB, some of the $\mathrm{O}$ atoms produce $\mathrm{CO}_{2}$ directly, which consumes two $\mathrm{O}$ atoms at one time, where only one $\mathrm{O}$ atoms would be needed to remove the $\mathrm{C}$ atom from sooting. Thus the second $\mathrm{O}$ atom is, in a sense, wasted and does not deactivate another $\mathrm{C}$ atom. Soot growth has been addressed by numerous modeling activities. For example, soot polymerization kinetics have been the subject of recent studies by Violi, Kubota and colleagues [188]. This is a classic multiscale problem, combining slow kinetic processes with much faster relaxation processes to redistribute energy throughout the adduct species. These studies make it possible to study the part of the soot production stage where small chemical species and primarily planar molecules grow and become gradually more spherical, thereby becoming similar to familiar soot, as illustrated in Fig. 10.

The ability of current models to connect the major elements of diesel combustion in this way lends credibility to both the conceptual model and to the chemical kinetic and physical submodels that have been developed. Some major problems remain, including the initial ignition when the air in the combustion chamber is still cold, and the soot burnout period has received very little attention. However, these steps are less challenging when approached within a sound conceptual framework than using overal concepts from the past. In this way, combustion modeling combined with experimental insights have genuinely revolutionized the analysis of diesel combustion in the past 10 years. 


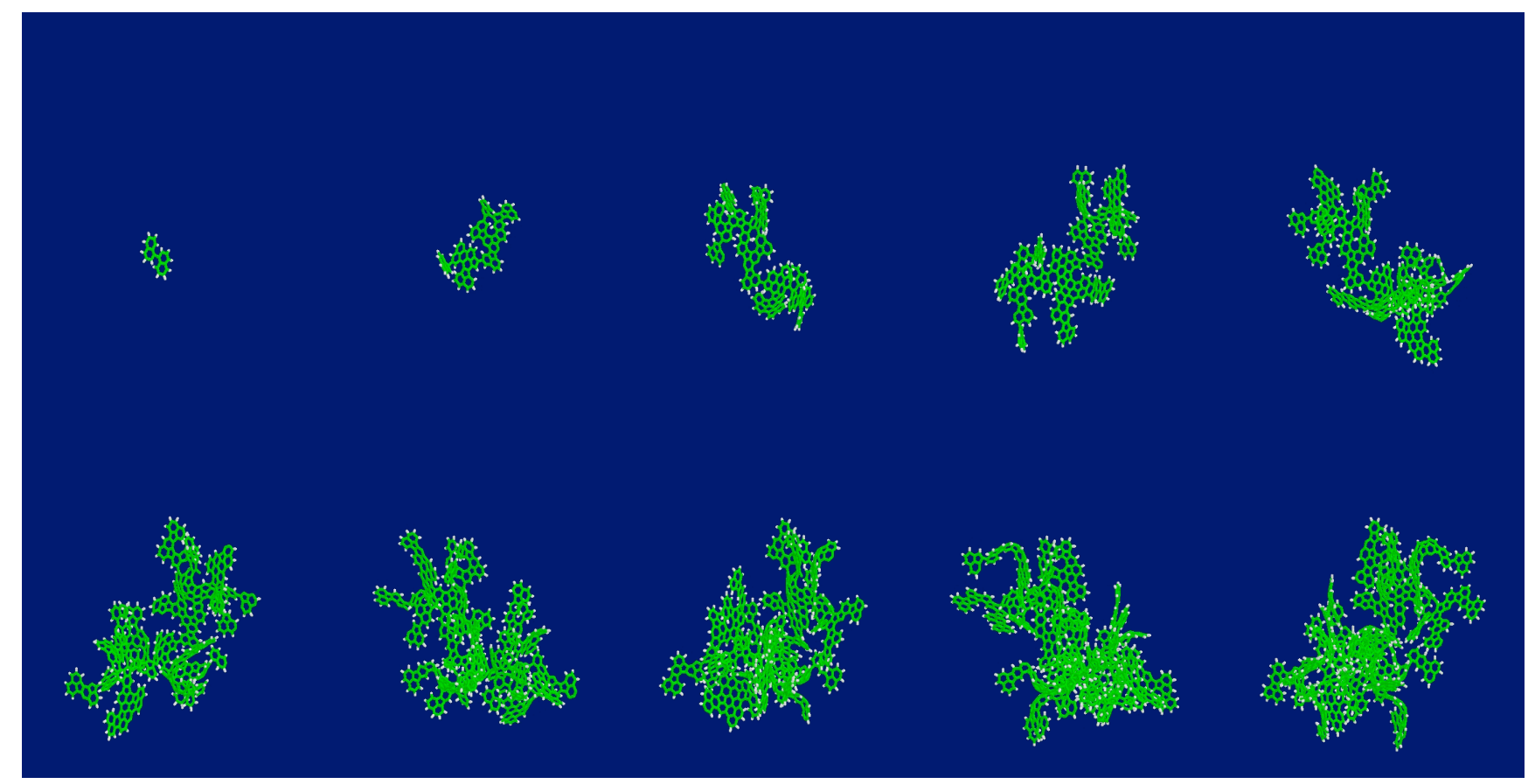

Fig. 10. Evolution of soot particle from gradual addition of small hydrocarbon fragments, from Violi et al. [130].

The conceptual model we are using here from Dec is radically different from previously held views, but it is only the first in what will certainly be a series of further modifications. Not all diesel cycles are alike, and this picture will not apply especially well to environments in which, for instance, the liquid jet penetrates through the chamber and impacts the far wall of the combustion chamber. Its value is in forcing modeling approaches to describe a new set of scenarios which connect the ignition to the soot production. As refinements are found, the overall predictive capability of diesel models will continually improve. The overall picture describes so many features of diesel combustion so accurately that it is already an enormous improvement over earlier concepts, but we look forward to new details that will further enhance the modeling description of diesel combustion. 


\section{$\underline{\text { HCCI engines }}$}

The concept of the homogeneous charge, compression ignition (HCCI) engine has existed for many years. However, in the past ten years a combination of aggressive experimental engine development and computational modeling has changed the $\mathrm{HHCI}$ engine from an idealized "virtual" engine into a genuine competitor to the spark ignition and diesel engines for multiple applications to stationary and mobile power production. For all practical purposes, it is the first major engine concept to be born during the computerized era, and its rapid growth from idea to hardware is an excellent lesson in the impact computational combustion has played in its rapid development.

In an ideal HCCI engine cycle, premixed gaseous fuel and air are introduced into the combustion chamber of a conventional piston engine at a very lean equivalence ratio. The equivalence ratio is considerably less than the lean flammability limit of the fuel, so no flame propagation is possible. This homogeneous but lean mixture is then ignited upon compression by piston motion. Ignition is approximately uniform throughout the chamber volume. Because the mixture is so lean $(0.2 \leq \phi \leq 0.4)$, the product temperature is too low to produce significant amounts of $\mathrm{NO}_{\mathrm{x}^{\prime}}$ and because the mixture is both lean and gaseous, no soot or unburned hydrocarbons are produced. Since the mixture is so lean, and to accomplish compression ignition, large compression ratios (CR 15-20) are used, giving the combustion good thermodynamic efficiency.

The most important experimental development of HCCI has been led by Johansson at Lund University in Sweden $[189,190]$, and as this group began to test these engines, the actual performance of their engines met some of the ideal 
goals but were seriously deficient in other areas [191]. Extremely low NOx values were achieved and no soot was observed, and the engine was found to perform well with a wide range of fuels ranging from high octane natural gas, propane and gasoline as well as very low octane fuels such as diesel fuel, but unacceptably high levels of unburned hydrocarbons and $\mathrm{CO}$ were observed, and the engine was very difficult to control.

Combustion modeling stepped in almost immediately and provided much-needed explanations for the observed behavior of the HCCI engine, and suggestions for solving the problems were available in an extremely timely manner. Computer analysis showed that the high levels of $\mathrm{CO}$ and unburned hydrocarbons were due to the presence of extended thermal boundary layers in the combustion chamber, which were much more extended than thermal boundary layers in SI engines; the fuel in these layers either did not ignite and burn at all, or it was incompletely consumed and produced the large amounts of $\mathrm{CO}$ that were observed. The same boundary layers had a beneficial effect as well, however; since the temperature is the major variable producing ignition, the lower temperatures in the extended boundary layer made them ignite later than the gases in the center of the combustion chamber, thereby spreading the heat release and pressure rise of the combustion over a time interval of 5-10 crank angle degrees. Without this more extended time interval for pressure rise, an extremely rapid pressure rise would produce engine damage and poor performance. In addition to the boundary layers, unburned fuel is found in piston ring crevices, just as in conventional engines, but in contrast, very little of this fuel is ever consumed because the engine chamber temperature is too low when piston motion releases this fuel into the combustion chamber. 
Combustion modeling groups led by Aceves, Mauss, Fiveland, Rutland and others [192-196] have attacked this problem with considerable energy, resulting in rapid evolution of the experimental engine designs. Interestingly, there seems to be no controversy as to the value of computer modeling of HCCI combustion; all of the disputes are related to which modeling approach is most useful. As usual, the answer is that each approach has its uses.

A single zone or homogeneous kinetic model seems to be most efficient in predicting the onset of ignition. The key to this capability is the availability of reliable chemical kinetic reaction mechanisms for the fuels of interest for HCCI. In the case of single-component fuels and for natural gas, these mechanisms have been extensively validated, making the predictions very reliable. To predict the burn duration, unburned hydrocarbons and most other quantities, a multizone simulation is generally required, and a number of such models have been developed. In order to limit the computer time requirements, and in recognition of the dominant effect of combustion temperature on ignition, the majority of these multizone approaches used CFD modeling very strategically, to resolve the spatial temperature variations due to wall boundary layers, often using a full 3D CFD model and an enormous number of spatial zones. This can identify the portions of the combustion volume in each temperature range at the time when appreciable rates of chemical reaction begin to occur. When reaction begins, these models then transition to calculations in which the kinetics play the dominant role and a much smaller number of zones are used. An example of the results of such an approach are shown in Fig. 11. 


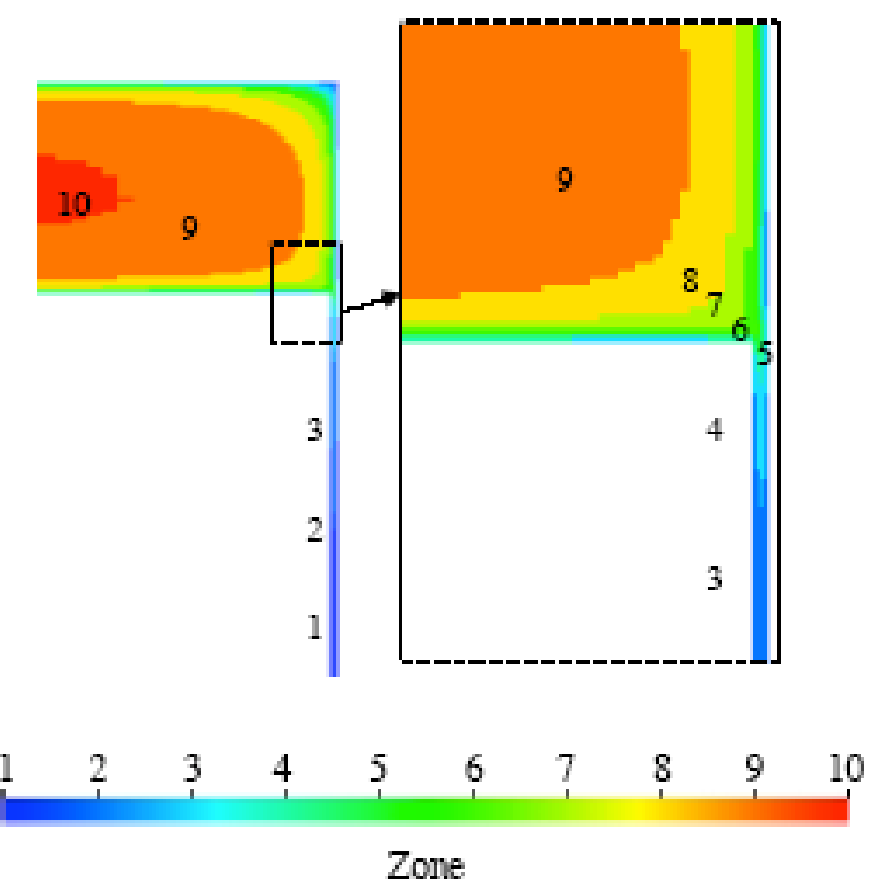

Fig. 11. Cross sectional view of HCCI engine combustion chamber [192]. At left is the entire chamber, with the numbers indicating which masses in the 3D CFD calculation will be collected into each of the 10 zones for the kinetics simulation. At the right is the blowup of the region close to the entrance of the piston ring crevice showing the cold gases in zones $1-4$.

Strategies for improving engine control and reducing the unburned hydrocarbon and $\mathrm{CO}$ emissions can be studied first in the models, reducing the cost and time of engine development significantly. For example, since the low product temperatures so essential to elimination of NOx can be achieved by dilution by exhaust gas recirculation (EGR), near-stoichiometric fuel/oxygen mixtures can be used and the ignition timing can then be varied by changing the EGR level during operation, thereby providing a source of engine control missing in the original HCCI concept.

HCCI has grown from an idea to reality in a very short time, and computational combustion has been a major contributing factor. Comparison of this evolution to that of SI and diesel engines is a nice illustration of the benefits 
of computer analysis in engine design. Of course, other factors such as advances in engine diagnostics have had a parallel evolution and have also made essential contributions, but computer simulations have had a unique impact on the HCCI concept. 


\section{Current capabilities}

\section{Turbulent non-premixed hydrogen jet flame}

Turbulence and turbulent combustion have been a driving force of computer development. Development of computational resources and parallelization techniques allows us to conduct hugely massive computations of a 3-D unsteady computation with several hundred millions or more than one billion grid points. In particular, using the worldwide fastest and largest computer system, the "Earth Simulator", a challenging direct numerical simulation (DNS) of homogeneous turbulence with $4096^{3}$ grid points has been carried out [197]. The DNS of turbulent channel flow has been also been conducted actively in Japan. The DNS with friction Reynolds number (Re _) over 1000 has been achieved $[198,199]$ to examine the significance of large structures away from the wall as well as small structures near the wall.

In the case of combustion DNS, which requires the solution of the 3-D Navier-Stokes equations, coupled with the equations of chemical species conservation, the maximum number of grid points must be smaller than for the turbulent flow alone, due to the necessity of additional computer memory and even more severely due to the need for increased computation time when the chemical kinetic equations must also be solved. In Japan, Tanahashi et al. carried out the first 3D chemically reactive combustion DNS (with about 5 million grid points), simulating a hydrogen/air premixed flame to study the effect of coherent fine-eddies on the combustion [200]. Nishiki et al. conducted a DNS of a premixed flame with an irreversible single step reaction to construct a combustion model in terms of a progress variable [201]. Recently some larger 
computer systems have been installed in Japan, making possible a billion grid point DNS of a hydrogen flame, as well as a DNS of a methane flame with as much as a hundred million grid points. We are approaching the exciting point where a DNS of a real size flame (or at least laboratory size) is becoming possible.

Most direct numerical simulations employ explicit time integrations. However, because a combustion or other reactive flow DNS has to resolve the fluid motions as well as the chemical reactions in the reacting layers, fine grid spacing is required, resulting in very small time steps due to the CFL condition for the convective terms, the time scale for the diffusion terms, and the stiff chemical reactions. In ordinary CFD simulations of reactive flows, the time step restriction from the stiff chemical reactions is very short compared with theCFDrelated time step limits, but in direct numerical simulations of combustion systems, the time step restrictions are almost equivalent, and no special treatment is needed to account for the stiffness of the chemical terms.

As an example of the frontier in massively parallel computational combustion, a simulation of a hydrogen jet lifted flame by Mizobuchi et al. [202] two years ago at the 29th Symposium succeeded in capturing a hydrogen jet lifted flame using a DNS approach with about 23 million grid points. Very recently, the same group carried out a simulation of the same flame configuration with hundreds of millions of grid points to understand in even greater detail the combustion phenomena in the lifted flame, and also to assess the solution dependency on grid resolution [203]. The computation with 200 million grid points is reported here. 
The lifted flame configuration follows the experiment by Cheng et al. [204]. A hydrogen jet is injected into still air from a round nozzle whose diameter $D$ is $2 \mathrm{~mm}$. The jet velocity is $680 \mathrm{~m} / \mathrm{sec}$, the Mach number is 0.54 and the Reynolds number based on the diameter is 13600 . In the experiment, a lifted flame with the lift-off height of 7 diameters was observed. The 9-species $\left(\mathrm{H}_{2}, \mathrm{O}_{2}\right.$, $\mathrm{OH}, \mathrm{H}_{2} \mathrm{O}, \mathrm{H}, \mathrm{O}, \mathrm{H}_{2} \mathrm{O}_{2}, \mathrm{HO}_{2}, \mathrm{~N}_{2}$ ) and 17-reaction model by Westbrook [205] is employed. The air is assumed to be composed of $22 \% \mathrm{O}_{2}$ and $78 \% \mathrm{~N}_{2}$ by volume. The thermal and transport properties of the gas mixture are calculated rather rigorously. The diffusion flux is evaluated using Fick's law with binary diffusion coefficients. The viscosity, heat conductivity and binary diffusion coefficient, are evaluated using the Lennard-Jones intermolecular potential model [206] and those of the gas mixture are calculated by Wilke's empirical rule [207]. The enthalpy of each chemical species is derived from JANAF [208]. The governing equations are the compressible three-dimensional Navier-Stokes equations, the conservation equations of total energy and chemical species and the equation of state. The equation of total mass conservation is also solved.

The main computational grid system is a rectangular grid which covers the overall computational domain of $-14 D<x, z<14 D,-2.5 D<y<20 D$, where the $\mathrm{y}$-direction is the jet axial direction, the $\mathrm{x}$ - and $\mathrm{z}$-directions are normal to the $y$-direction and the coordinate origin is the jet exit center. The grid spacing is $0.05 \mathrm{~mm}$ in the region closest to the nozzle, $-5 D<x, z<5 D$ and $-0.3 D<y<15.2 D$. The grid spacing is about 2.5 times as large as the Kolmogorov scale around the base flame estimated in the corresponding experiment and is about $1 / 10$ of the heat release layer width of the one-dimensional stoichiometric laminar premixed 
flame calculated by PREMIX [209]. The grid spacing increases in geometrical progression as the distance from the above mentioned region increases. A cylindrical grid system is patched around the nozzle tube, which covers the region of $0.4 D<\left(x^{2}+z^{2}\right)^{1 / 2}<0.7 D,-2.5 D<y<2.2 D$. The coarsest grid spacing in the second grid system is about $0.05 \mathrm{~mm}$. The total number of the grid points is about 200 million.

The discretization is based on a finite volume method. The convective terms are evaluated using an upwind TVD (Total Variation Diminishing) numerical flux based on Roe's approximate Riemann solver [210,211]. The higher-order flux is constructed extrapolating the characteristics using two types of flux limiters[212]. The accuracy of this flux is third-order in smooth regions and keeps second-order around regions where the sign of characteristics gradient changes. The viscous terms are evaluated with standard second-order difference formulae. The diffusion fluxes at the cell interfaces are modified so that the total mass is conserved. The time integration is done by the second-order RungeKutta multi-stage method. For the details of the discretization method, see [213]. The nozzle surface is assumed to be a slip wall. On the jet exit the axial velocity is extrapolated, the total pressure and the total temperature are fixed to the values which realize a $1 / 7$ power law velocity profile when the exit pressure is atmospheric, and no artificial disturbance is imposed. At the far field boundaries the non-reflection condition $[214,215]$ is applied and the total pressure and the total temperature are fixed at the inlet boundary.

The computation is carried out using the SMP cluster system, Central Numerical Simulation System (CeNSS), installed at Aerospace Research Center 
(ARC) of Japan Aerospace Exploration Agency (JAXA). The computational domain is decomposed into 75 sub-blocks and each of them is assigned onto one computer process. The communication among the processes is implemented by use of MPI. Each process includes multi-processors and OpenMP is used for the parallelization inside the process. In total, 291 processors are used.

The simulation represents a strongly three-dimensional and turbulent hydrogen jet flowfield as shown in Fig.1 (a) which shows the instantaneous isosurface of the hydrogen mole fraction at $60 \%$. Fig.1 (b) shows the instantaneous iso-surface of the hydrogen consumption rate at $10^{4} \mathrm{~mol} / \mathrm{sec} / \mathrm{m}^{3}$. A stable lifted flame solution is obtained in the same way as in our previous computation and in the referred experiment, although the lift-off height is slightly shorter than in the experiment. The global structure of the lifted flame is clearly illustrated by use of flame index (F.I.) [216], which is defined as

$$
F . I .=\nabla Y_{\mathrm{H}_{2}} \cdot \nabla Y_{\mathrm{O}_{2}}
$$

where $Y_{\mathrm{s}}$ is the mass fraction of species s. The local combustion mode is premixed when F.I. is positive and diffusive when negative. The color of the isosurface in Fig.1 (b) shows the local combustion mode as determined by the local flame index and the local mixture fraction in Bilger's definition [217]. The red, blue and green surfaces correspond to rich premixed, lean premixed and diffusion flames, respectively.

One can see that the jet lifted flame is not a single flame, but consists of the three flame elements; (1) a leading edge flame, (2) an inner rich premixed flame, and (3) outer diffusion flame islands. The leading edge flame, which is composed of rich/lean premixed flames and diffusion flames, stabilizes the 
global system of the lifted flame, although it is strongly 3-D and unsteady. The inner rich premixed flame is vigorously turbulent and the structure of the reaction layer is so much disturbed that the laminar flamelet concept cannot be applied. The outer diffusion flames are not stabilized at the fixed positions but flow slowly downstream along the stoichiometric plane and take island-like discrete forms. Detailed investigations into each flame element are expected to bring novel information on combustion and contribute to combustion modeling.

Historically, most turbulent flame analyses have been based on laminar flame theory, but the regime over which laminar flame theory may be applied is limited, and not all flames can be described accordingly. "Real size" flame DNS has the potential to describe flames to which the laminar flame concept cannot be applied, as illustrated by the flame described above, with its vigorously turbulent inner rich premixed flame in the hydrogen jet lifted flame. In such cases, it is necessary to develop analytical methods based on new concepts as we begin to tackle the new phenomena discovered by the next generation of DNS.

Implementation of this kind of hugely massive computation raises new problems, especially with respect to post-processing and understanding the data obtained. The amount of data and complexity of the solution might be beyond the understanding capability of human beings, and it will limit the progress of combustion science compared to the very rapid development of the computer performance.

Even the data format can be a serious problem. For example, one of the common formats of CFD data is PLOT3D. Many CFD researchers use various versions of FORTRAN, and data I/O is made in FORTRAN unformatted form. FORTRAN unformatted form has a strict limit in the vector length of $2 \mathrm{~GB}$, a 
limitation that is now becoming very critical when we use commercial postprocessing software which uses PLOT3D format.

From the viewpoint of the hardware, we need huge amounts of storage, because post-processing produces even larger amounts of data than the raw data from combustion DNS. Post-processing computers must have large memories, computing power and visualization performance. For all of these reasons, parallel post-processing will be indispensable in the near future, and close collaboration between combustion researchers and computer scientists will become extremely important.

a)

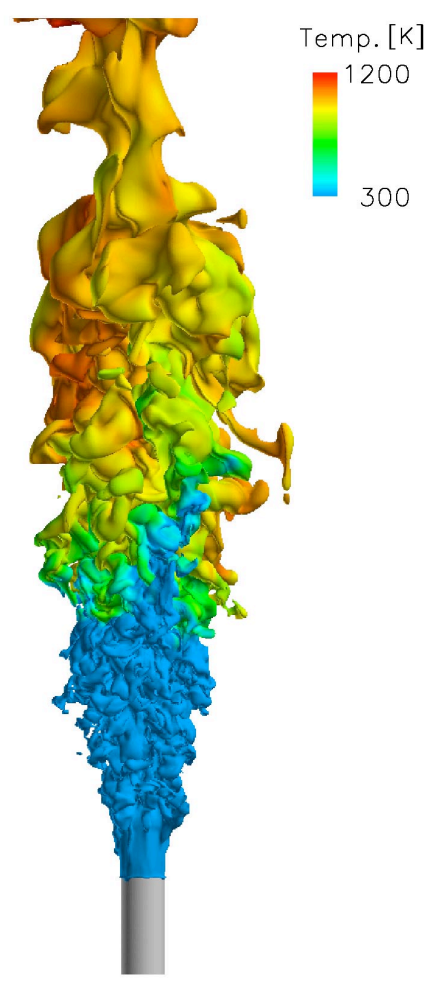

b)

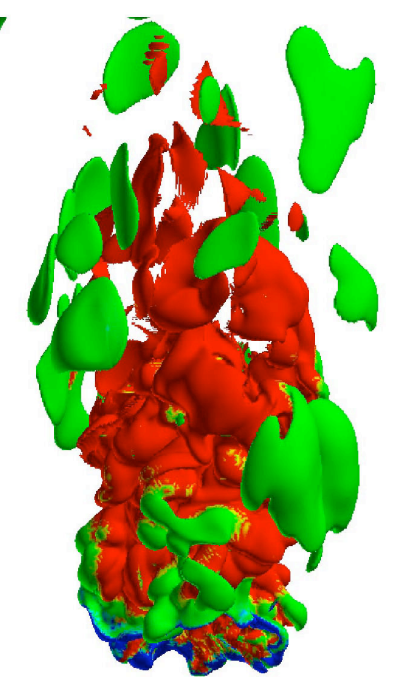

Fig. 12 Overview of the simulated hydrogen jet lifted flame. a): instantaneous isosurface of the hydrogen mole fraction at $60 \%$ with the temperature distribution on the surface. b): instantaneous iso-surface of hydrogen consumption rate at $10^{4} \mathrm{~mol} / \mathrm{sec} / \mathrm{m}^{3}$, where the surface color presents the combustion mode, red: rich premixed, blue: lean premixed, green: diffusive. 


\section{The DNS/LES revolution}

Turbulent combustion is the most common regime in practical flame applications. In the development of numerical combustion, it was soon recognized that most numerical tools developed for laminar flames could not be used for turbulent cases because of the unsteady three-dimensional nature of the interaction between turbulence and flame. Understanding the unsteady phenomena controlling flame / turbulence interaction was abandoned and models aimed only at the prediction of mean quantities, for example time averaged temperature or species fields. Numerical turbulent combustion developed mainly using so-called RANS (Reynolds Averaged Navier Stokes) equations which predict average quantities. To close the conservation equations for average velocities, species and temperature, a variety of assumptions were used and the literature between 1960 and now shows how different these models can be [218-220]. Two facts illustrate the difficulty of these approaches: (1) even though most companies have CFD codes for reacting flows, the most widely used turbulent combustion model in these codes is still one the first which was developed: the Eddy Break Up model [221] and (2) the absolute predictive capabilities of turbulent combustion codes are not sufficient in many practical combustor developments.

One of the reasons for this is the obvious difficulty of coupling complex kinetics and turbulence. Another one is the averaging approach itself used in RANS in which only mean quantities were measured and computed while the details of the interaction were largely ignored. Numerical combustion revolutionized the way these models were built at the end of the 1970's by introducing Direct Numerical Simulations (DNS) in which the basic mechanisms 
controlling the interaction of a flame with an unsteady flow were investigated using advanced (and expensive) CFD tools [222-224]. Obviously, this was made possible first by using drastic assumptions such as constant density, simplified kinetics, two-dimensional flows and simplified transport models. However, even these approximate results were providing a better basis for model development than the educated guesses which had been used before. The first generation of DNS brought essential information on flame vortex interaction computations [225-228], flame turbulence interaction [229-231] or flame/wall interactions $[232,233]$. This new numerical approach for turbulent combustion even generated new experiments: flame/vortex interaction studies, for example, were developed to be compared with DNS [234-237]. Many present RANS models contain data which directly come from DNS [238-240].

DNS have evolved rapidly since the 1980's and present DNS can incorporate most of the detailed physics required to simulate quantitatively flame/turbulence interaction. Many DNS now integrate complex kinetics $[241,242]$ and most of them are performed in three dimensions. Synthetic turbulent fields are generated to mimic turbulent flows and injected in computation inlets, as shown in Fig. 13 from Vervisch [243].

Although most DNS are dedicated to the computation of a small part of a flame, some recent DNS tools have reached sufficient maturity to compute a complete flame as long as the geometry remains simple, as demonstrated in the previous example from Mizobuchi et al. [203]. 


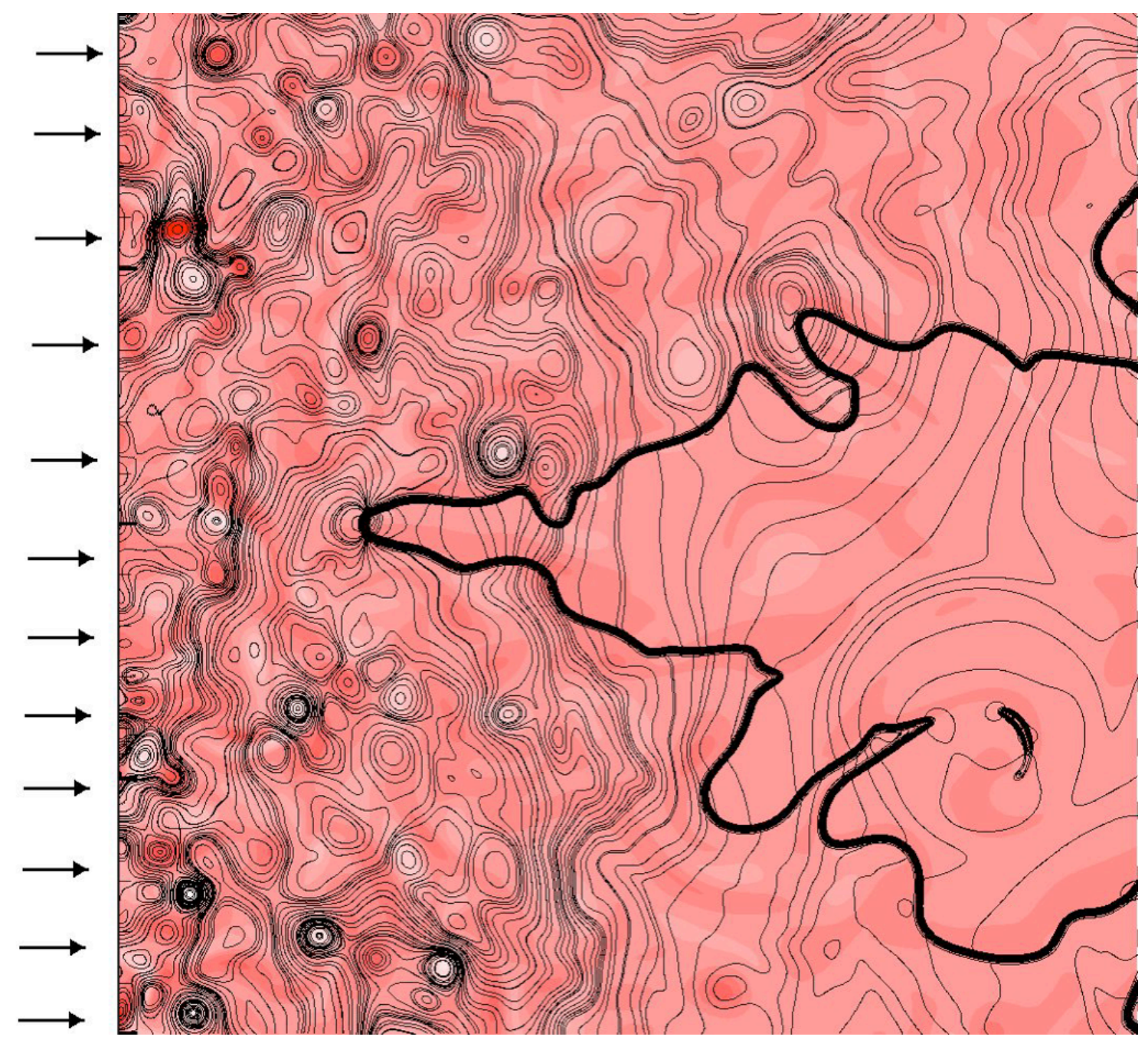

Figure 13. Example of DNS of stabilized premixed flame [243]: turbulence is injected on the left boundary; the flame is stabilized on a hot spot. The flame position (thick line) is superimposed on pressure isolines.

The most significant drawbacks of DNS codes were and still are their limitation in terms of Reynolds number (only small, low-power devices can be computed) and of geometrical complexity (only simple shape chambers can be considered). The second numerical revolution in this field at the end of the 
1990's was the development of LES (Large Eddy Simulation) methods for reacting flows which can be applied to high-Reynolds complex combustion chambers. Even though these methods model small scale turbulent motion, they still offer a significant improvement on classical RANS techniques because large scale perturbations are explicitly captured. LES is now developing rapidly even for industrial applications.

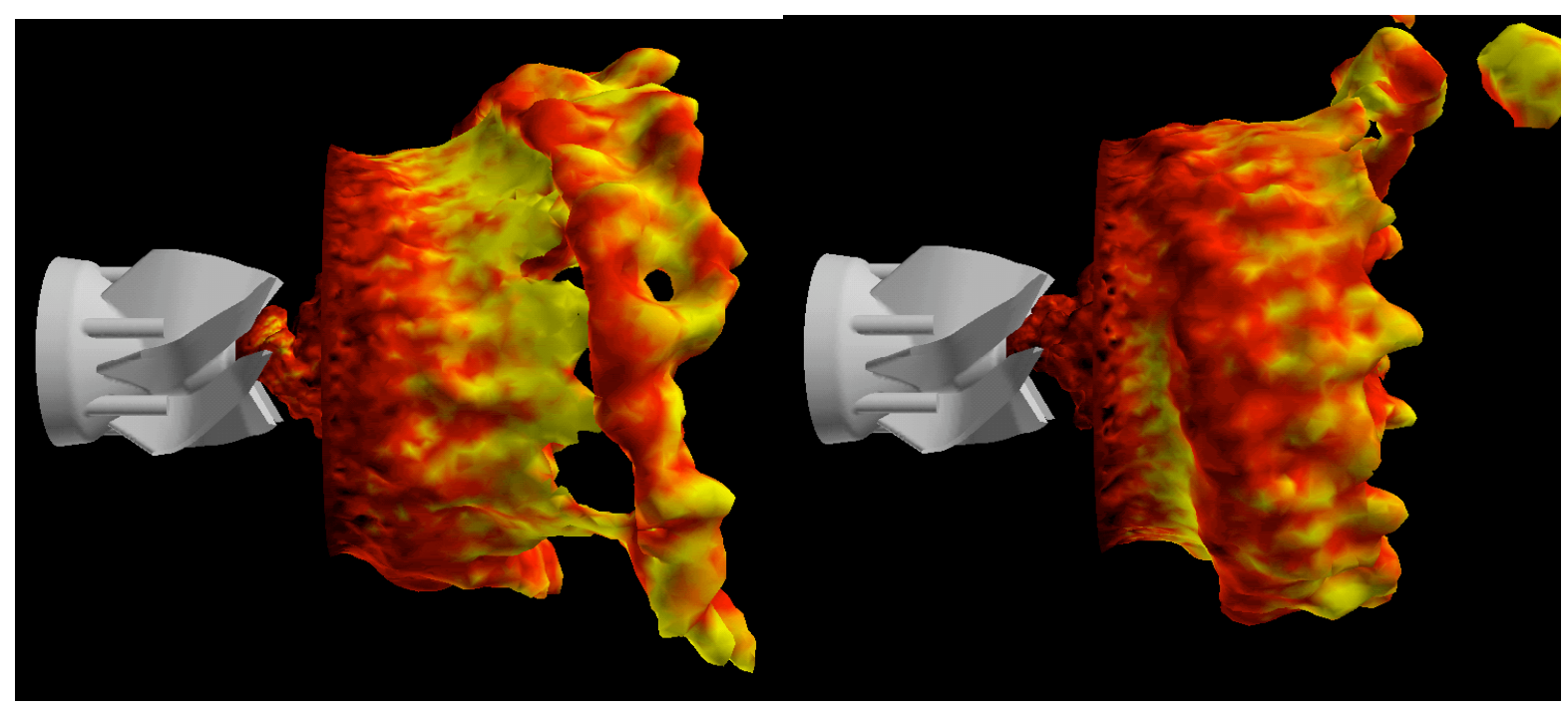

Figure 14. Isosurfaces of temperature $\mathrm{T}=1000 \mathrm{~K}$ at two instants of the $1200 \mathrm{~Hz}$ cycle separated by a half period. The turning mode shapes the flame along a spiral motion.

LES for reacting flows allows more precise computations of turbulent flames but also opens new perspectives to compute the interaction between combustion and acoustics, especially combustion instabilities which are a serious problem in many combustion devices $[27,28]$. LES is especially well adapted to the study of 
these phenomena which are controlled by large scale vortices (explicitly captured in LES) and acoustic waves (also easily tracked using high-order schemes typically found for LES). As an example, Fig.14 shows a LES of combustion in an industrial gas turbine [29] where the flame is stabilized by intense swirl and a central recirculation zone. The Reynolds number is very large and the flame is partially premixed. For such configurations, present LES tools use hybrid meshes which can handle any complex geometry [30,31]. In the present case, an acoustic turning mode at $1200 \mathrm{~Hz}$ controls the flame shape: the acoustic velocity induced by the turning mode at the swirler mouth creates a helicoidal perturbation which is convected downstream and slices flame elements when it reaches the flame extremities.

\section{Discussion and Conclusion}

We expect Moore's Law to continue for the foreseeable future, so the capacity of approaching computing systems will be available for many types of important and insightful computations. Computer modeling tools are growing as well, although perhaps not as rapidly as the computer hardware.

We have described two different responses of the combustion modeling community to this enormous growth in computing power. The first has been the ability to model much larger systems; in some systems, the really interesting systems are unavoidably large, such as in fuel kinetics, where hydrogen and methane have taught us a great deal, but gasoline, diesel fuel, and jet fuel are the fuels of everyday life. In turbulence phenomena, the ability to simulate the different spatial scales is essential, and the ability to resolve spatial scales in 
engine and burner applications also requires very large numbers of spatial zones. The LES and DNS examples above illustrated some of these factors.

In addition to issues of pure size, advances in compute power are making it possible for combustion modeling to deal with increased and more realistic complexity in simulations. We are overcoming the necessity of relying on removing parts of simulations that we know are important but cannot treat in a coupled model. The pool fire and surface combustion descriptions and the DNS flame above are good examples of this change in the computational rules of engagement. Idealized geometries and 1D problems with full kinetics will still be used, but they will be applied to conceptual problems where they have the best value, not to engine or burner simulations where they have been an unhappy but necessary concession to the disappearing limits to computing power. Of course, the fact that the DNS flame must be used with simplified geometry, that the burners must use methane or hydrogen in their 3D treatments, and that the engine simulations cannot fully resolve their flows or the details of piston ring crevices, are all testaments to the fact that further advances in computing capacity will still be important. However, recent advances in problem complexity are probably the most significant new development in computational combustion and offer potential new insights that will develop into advanced implementations.

We have seen and described above how new combustion systems will be tested in some cases before they are built. The dramatically larger role of computing in the growth of the HCCI engine concept is a perfect illustration of this trend, and the same approach is currently being used for gas turbines, solid fuel propulsion systems, and others. Computers and computer modeling are 
now mature, powerful tools and are playing roles in practical system design along with the laser and more traditional techniques. As noted above, it seems possible that our ability to visualize and understand our model simulations may soon limit our rate of growth in problem size and complexity, rather than be limited by disappointing computer power.

While a considerable number of model systems have been summarized and some important types of applications have been outlined, the present paper cannot deal with all of the breadth of computational combustion. Many interesting areas have been noted very briefly and others completely omitted, simply for lack of time and space. We have given particular attention to those areas in which the authors are directly involved, and we regret not being able to give full attention to many other topics. It is a measure of the vitality and relevance of combustion modeling that it cannot be described adequately in this type of review. In this view, and to perhaps make this contribution useful to those who might want to use it as a starting point for further study, we want to provide citations to a number of valuable and general sources.

Prominent in this field is the book "Numerical Simulation of Reactive Flow" by Oran and Boris [249] and the volume edited by the same authors with contributions on important special topics, "Numerical Approaches to Combustion Modeling" [250]. Recent valuable texts by experts have already been cited above $[114,220]$. Early works on engine combustion by Bracco [251253] were directed specifically towards modeling. Many reviews of specific topical areas have been published and some have been cited above, including those describing different approaches to modeling sprays, premixed laminar flames, and others, but we cannot cite or be aware of them all. 


\section{ACKNOWLEDGMENTS}

The authors are pleased to recognize and thank Bill Pitz, Tom Jackson, David Torres, Luc Vervisch, Cindy Atherton, Elaine Oran, Ron Hanson, and Peter Lindstedt for special inputs in the form of direct help, figures and animations for the paper and presentation, editing of the early drafts, and the invitation to prepare this paper. Portions of this work were performed under the aspices of the U.S. Department of Energy at Lawrence Livermore National Laboratory under Contract No. W-7405-ENG-48.

This work was performed under the auspices of the U. S. Department of Energy by University of California, Lawrence Livermore National Laboratory under contract No. W-7405-Eng-48. 


\section{References}

1. Courant, R., Friedrichs, K.O., and Lewy, H., Math. Ann., 100:32 (1928).

2. Richtmyer, R.D., and Morton, K.W., Difference Methods for Initial-Value Problems, Interscience Publishers, New York, 1967.

3. Supercomputing 88: Vol. II, Science and Applications, J.L. Martin and S.F. Lundstrom, eds., IEEE Computer Society Press, Washington, DC 1988.

4. $\quad$ Richardson, L.F., Weather Prediction by Numerical Process, Cambridge University Press, 1922. Reprinted by Dover Publications, New York, 1965.

5. Lynch, P., "Richardson's Marvellous Forecast", pp. 61-73 in The Life Cycles of Extratropical Cyclones, M.A. Shapiro and S. Grønas, Eds., Amer. Met. Soc., Boston, 1999.

6. Charney, J.G., Fjørtoft, R., and von Neumann, J., Tellus 2:237-254 (1950).

7. Alder, B.J., Killeen, J., and Rotenberg, M., Methods in Computational Physics, vol. 1, Academic Press, New York, 1965.

8. Alder, B.J., Killeen, J., and Rotenberg M., Methods in Computational Physics, vol. 7, Academic Press, New York, 1967.

9. Alder, B.J., Killeen, J., and Rotenberg, M., Methods in Computational Physics, vol. 9, Academic Press, New York, 1970.

10. Harlow, F., and Fromm, J.E., "Computer Experiments in fluid Dynamics", Scientific American 212:104-110 (1965).

11. Harlow, F., and Welch, J.E., Phys. Fluids 8:2182-2189 (1965).

12. Harlow, F., and Nakayama, P.I., "Transport of Turbulence Energy Decay Rate", Los Alamos Scientific Laboratory report LA-4086 (1968).

13. Launder, B.E., and Spalding, D.B., Mathematical Models of Turbulence, Academic Press, New York, 1972.

14. Amsden, A.A., Butler, T.D., O'Rourke, P.J., and Ramshaw, J.D., Society of Automotive Engineers publication SAE-850554 (1985).

15. Amsden, A.A., Butler, T.D., and O'Rourke, P.J., Society of Automotive Engineers publication SAE-872072 (1987).

16. Gosman, A.D., Pun, W.M., Runchal, A.K., Spalding, D.B., and Wolfshtein, M., Heat and Mass Transfer in Recirculating Flows, Academic Press, New York (1969). 
17. Patankar, S.V., and Spalding, D.B., Proc. Combust. Inst. 14:605 (1972).

18. Moore, G.E., Electronics, 38 (1965).

19. Spalding, D.B., Proc. Combust. Inst. 9:833-843 (1963).

20. Becker, H.A., Hottel, H.C., and Williams, G.C., Proc. Combust. Inst. 9:7-20 (1963).

21. Roache, P.J., Computational Fluid Dynamics, Hermosa Publishers, Albuquerque, 1982.

22. Noh, W.F., “CEL - A Time-Dependent, Two Space Dimensional, Coupled Eulerian-Lagrange Code", Lawrence Livermore Laboratory report UCRL7463 (1963).

23. Harlow, F.H., and Amsden, A.A., J. Comput. Phys. 8:197 (1971).

24. Rivard, W.C., Farmer, O.A., and Butler, T.D., "RICE - A Computer Program for Multicomponent Chemically Reactive Flows at All Speeds", Los Alamos Scientific Laboratory report LA-5812 (1975).

25. Hirt, C.W., Amsden, A.A., and Cook, J.L., J. Comput. Phys. 14:227 (1974)

26. Butler, T.D., Cloutman, L.D., Dukowicz, J.K., and Ramshaw, J.D., "CONCHAS: An Arbitrary Lagrangian-Eulerian Computer Code for Multicomponent Chemically Reactive Flow at All Speeds", Los Alamos Scientific Laboratory report LA-8129 (1979).

27. Westbrook, C.K., J. Comput. Phys. 29:67-80 (1978).

28. Yanenko, N.N., The Method of Fractional Steps, Springer Verlag, Berlin 1971.

29. www.icemcfd.com/cfd/CFD-codes.html

30. Hottel, H.C., and Sarofim, A.F., Radiative Transfer, McGraw Hill, New York, 1967.

31. Troe, J., Pilling, M.J., and Miller, J.A., Proc. Combust. Inst. 30:xx-xx (2004).

32. Curtiss, C.F., and Hirschfelder, J.O., Proc. Nat. Acad. Sci. 38:235-243 (1952).

33. Gear, C.W., Numerical Initial Value Problems in Ordinary Differential Equations, Prentice-Hall, Englewood Cliffs, NJ (1971).

34. Gear, C.W., "The Automatic Integration of Stiff Ordinary Differential Equations", pp. 187-193, Information Processing, A.J.H. Morrell, ed., NorthHolland, Amsterdam (1969). 
35. Hindmarsh, A.C., GEAR: Ordinary Differential Equation System Solver, Lawrence Livermore Laboratory report UCID-30001, Rev. 3 (1974).

36. Hindmarsh, A.C., and Byrne, G.D., EPISODE: An Effective Package for the Integration of Systems of Ordinary Differential Equations, Lawrence Livermore Laboratory report UCID-30112, Rev. 1 (1977).

37. Radhakrishnan, K., "Combustion Kinetics and Sensitivity Analysis Computations", pp. 83-128, Numerical Approaches to Combustion Modeling, E.S. Oran and J.P. Boris, eds., vol. 135 in Progress in Astronautics and Aeronautics, Washington, D.C., (1991).

38. Byrne, G.D., and Hindmarsh, A.C., J. Comput. Phys. 70:1-62 (1987).

39. Gelinas, R.J., J. Comput. Phys. 9:222-236 (1972).

40. Hirschfelder, J.O., Curtiss, C.F., and Campbell, D.E., J. Chem. Phys. 57:403 (1953).

41. Spalding, D.B., Phil. Trans. Roy. Soc. Lond. 249A:1-25 (1956).

42. Seery, D.J., and Bowman, C.T., Combust. Flame 14:37-48 (1970).

43. Bowman, C.T., Combust. Sci. Technol. 2:161-172 (1970).

44. Marteney, P.J., Combust. Sci. Technol. 1:461 (1970).

45. Smoot, L.D., Hecker, W.C., and Williams, G.A., Combust. Flame 26:323-342 (1976).

46. Tsatsaronis, G., Combust. Flame 33:217-239 (1978).

47. Bowman, C.T., Combust. Flame 25:343-354 (1975).

48. Westbrook, C.K., and Dryer, F.L., Combust. Sci. Technol. 20:125-140 (1979).

49. Westbrook, C.K., and Dryer, F.L., Proc. Combust. Inst. 18:749-767 (1980).

50. Westbrook, C.K., and Dryer, F.L., Prog. Energy Combust. Sci. 10:1-57 (1984).

51. Warnatz, J.,"Flame Velocity and Structure of Laminar Hydrocarbon-Air Flames", pp. 501-521, J.R. Bowen, N. Manson, A.K. Oppenheim, and R.I. Soloukhin, eds., Combustion in Reactive Systems, AIAA, New York, 1981.

52. Gardiner, Jr., W.C., and Edelson, D., Symposium on Reaction Mechanisms, Models, and Computers, J. Phys. Chem. 81:2309-2586 (1977).

53. Westbrook, C.K., Combust. Sci. Technol. 20:5-17 (1979). 
54. Frenklach, M., Wang, H., Goldenberg, M., Smith, G.P., Golden, D.M., Bowman, C.T., Hanson, R.K., Gardiner, W.C., and Lissianski, V., http://www.me.berkeley.edu/gre mech/ (1995).

55. Petersen, E.L., Davidson, D.F., and Hanson, R.K., Combust. Flame 117:272290 (1999).

56. Westbrook, C.K., Dryer, F.L., and Schug, K.P., Proc. Combust. Inst. 19:153166 (1982).

57. Notzold, D., and Algermissen, J., Combust. Flame 40:293-313 (1981).

58. Westbrook, C.K., and Pitz, W.J., Combust. Sci. Technol. 37:117-152 (1984).

59. Warnatz, J., Proc. Combust. Inst. 18:369-384 (1980).

60. Pitz, W.J., Westbrook, C.K., Proscia, W.M., and Dryer, F.L., Proc. Combust. Inst. 20:831-843 (1984).

61. Westbrook, C.K., Pitz, W.J., Boercker, J.E., Curran, H.J., Griffiths, J.F., Mohamed, C., and Ribaucour, M., Proc. Combust. Inst. 29:1311-1318 (2002).

62. Wagner, A.F., Proc. Combust. Inst. 29:1173-1200 (2002).

63. Ritter, E.R., and Bozzelli, J.W., THERM: Thermodynamic Property Estimation for Gas Phase Radicals and Molecules, 12th International CODATA Conference, 1990.

64. Benson, S.W., Thermochemical Kinetics, Wiley, New York 1976.

65. Gardiner, Jr., W.C., Combustion Chemistry, 2nd edition, Springer-Verlag, New York (2000).

66. Westbrook, C.K., Proc. Combust. Inst. 28:1563-1577 (2000).

67. Westbrook, C.K., and Dryer, F.L., Combust. Flame 37:171-192 (1980).

68. Westbrook, C.K., Pitz, W.J., Curran, H.C., Boercker, J., and Kunrath, E., Int. J. Chem. Kinetics 33:868-877 (2001).

69. Westbrook, C.K., Combust. Flame 46:191-210 (1982).

70. Day, M.J., Stamp, D.V., Thompson, K., and Dixon-Lewis, G., Proc. Combust. Inst. 13:705 (1971).

71. Westbrook, C.K., Combust. Sci. Technol. 34:201-225 (1983).

72. Glaude, P.-A., Curran, H. J., Pitz, W. J., and Westbrook, C. K., Proc. Combust. Inst. 28: 1749-1756 (2000). 
73. Pollard, R.T., "Hydrocarbons”, Ch.2, Comprehensive Chemical Kinetics, vol. 17, Gas-Phase Combustion (C.H. Bamford and C.F.H. Tipper, eds.), Elsevier, New York (1977).

74. Westbrook, C. K., Pitz, W. J., and Leppard, W. R., Society of Automotive Engineers publication SAE-912314 (1991).

75. Spalding, D.B., and Stephenson, P.L., Proc. Roy. Soc. Lond. A 324:315-3337 (1971).

76. Hirschfelder, J.O., Curtiss, C.F., Henkel, M.J., Spaulding, W.P., and Hummel, H., Proc. Combust. Inst. 3:121-139 (1949).

77. Hirschfelder, J.O., Curtiss, C.F., and Campbell, D.E., Proc. Combust. Inst. 4:190-211 (1953).

78. Fristrom, R.M., and Westenberg, A.A., Flame structure, McGraw-Hill, New York, 1965.

79. Lindsay, A.L., and Bromley, L.A., Ind. Engng. Chem. 42:1508 (1950).

80. JANAF Thermochemical Tables, Dow Chemical Company, Midland, Michigan, 1960.

81. Svehla, R.A., NASA Technical report R-132 (1962).

82. Dixon-Lewis, G., Phil. Trans. Roy. Soc. Lond. A 292:45-99 (1979).

83. Dixon-Lewis, G., Goldsworthy, F.A., and Greenberg, J.B., Proc. Roy. Soc. Lond. A 346:261 (1975).

84. Warnatz, J., Ber. Bunsen. Phys. Chem. 82:193-200 (1978).

85. Warnatz, J., Ber. Bunsen. Phys. Chem. 82:643-649 (1978).

86. Special Issue on Laminar Flame Propagation in Premixed Gases, C.K. Westbrook and J.A. Miller, eds., Combust. Sci. Technol., volume 34 (1984).

87. Kee, R.J., Miller, J.A., and Jefferson, T.H., CHEMKIN: A General-Purpose, Problem-Independent, Transportable, FORTRAN Chemical Kinetics Code Package", Sandia Laboratories report SAND80-8003 (1980).

88. Reaction Design, http://www.reacctiondesign.com/

89. Goodwin, D.G., "An open-source, extensible software suite for CVD process simulation," in Chemical Vapor Deposition XVI and EUROCVD 14, edited by M. Allendorf, F. Maury and F. Teyssandier, Electrochemical Society, pp. 155-162 (2003) dgoodwin@caltech.edu. 
90. Hsu, D.S.Y., Hoffbauer, M.A., and Lin, M.C., Surf. Sci. 184:25 (1987).

91. Ruf, B., Behrendt, F., Deutschmann, O., Kleditzsch, S., and Warnatz, J., Proc. Combust. Inst. 28:1455-1461 (2000).

92. Bond, G.C., Heterogeneous catalysis: Principles and applications, 2nd ed., Oxford Press, Oxford, 1990.

93. Christmann, K., Introduction to surface physical chemistry. Springer, Berlin/Heidelberg, 1991.

94. Coltrin, M.E., Kee, R.J., Rupley, F.M., Int. J. Chem. Kinet. 23:1111 (1993).

95. Hellsing, B., Kasemo, B., Ljungström, S., Rosen, A., and Wahnström. T., Surface Sci. 189/190:851 (1987).

96. Hellsing, B., and Kasemo, B., Chem. Phys. Lett. 148:465 (1988).

97. Ljungström, S., Kasemo, B., Rosen, A., Wahnström, T., and Fridell, E., Surf. Sci. 216:63 (1989)

98. Williams, W.R., Marks, C.M., and Schmidt, L.D., J. Phys. Chem. 96:5922 (1992).

99. Song, X., Williams, W.R., Schmidt, L.D., and Aris, R., Proc. Combust. Inst. 23:1129 (1991).

100. Warnatz, J., Proc. Comb. Inst. 24:553-579 (1992).

101. Warnatz, J., Allendorf, M.D., Kee, R.J., and Coltrin, M.E., Combust. Flame 96:393-406 (1994).

102. Ikeda, H., Libby, P.A., Williams, F.A., and Sato, J., Combust. Flame 93:138148 (1993).

103. Deutschmann, O., and Schmidt, L.D., Proc. Combust. Inst. 27:2283-2291 (1998).

104. Hickman, D.A., and Schmidt, L.D., AIChE J., 39:1164-1177 (1993).

105. Deutschmann, O., Schmidt, L.D., and Warnatz, J., "Simulation of reactive flow in a partial oxidation reactor with detailed gas phase and surface chemistry models", F. Keil, W. Mackens, H. Voss, and J. Werther, editors, Scientific Computing in Chemical Engineering and Molecular Properties, pp. 368 - 375. Springer, 1999.

106. Deutschmann, O., Schwiedernoch, R., Maier, L.I., and Chatterjee, D., "Natural Gas Conversion in Monolithic Catalysts: Interaction of Chemical 
Reactions and Transport Phenomena", Natural Gas Conversion VI, Studies in Surface Science and Catalysis 136 (E. Iglesia, J.J. Spivey, T.H. Fleisch (eds.), pages 215-258. Elsevier, Amsterdam, 2001.

107. Braun, J., Hauber, T., Többen, H., Windmann, J., Zacke, P., Chatterjee, D., Correa, C., Deutschmann, O., Maier, L., Tischer, S., and Warnatz, J., Society of Automotive Engineers paper 2002-01-0065 (2002).

108. Chatterjee, D., Deutschmann, O., and Warnatz, J., Faraday Discuss. 119:371384 (2001).

109. Windmann, J., Braun, J., Zacke, P., Tischer, S., Deutschmann, O., and Warnatz, J., Society of Automotive Engineers paper 2003-01-0937 (2003).

110. Zhu, H., Kee, R.J., Janardhanan, V.M., Deutschmann, O., and Sullivan, N.P., J. Electrochemical Soc., submitted 2004.

111. Behrendt, F., Deutschmann, O., Maas, U., and Warnatz, J., J. Vac. Sci. Technol. 13:1373-1377 (1995).

112. Bar, E., and Lorenz, J., Appl. Surf. Sci. 91:321-325 (1995).

113. Kissel-Osterrieder, R., Behrendt, F., and Warnatz, J., Proc. Combust. Inst. 28:1323-1330 (2000).

114. Warnatz , J., Maas, U., and Dibble, R.W., Combustion. Springer, Heidelberg 3rd edition (2001).

115. Lauterbach, J., Asakura, K., and Rotermund, H.H., (1995) Surf. Sci. 313:52 (1995).

116. Härle, H., Lehnert, A., Metka, U., Volpp, H.R., Willms, L., and Wolfrum, J., Chem. Phys. Lett. 293:26 (1998).

117. Pery, T., Schweitzer, M.G., Volpp, H.-R., Wolfrum, J., Ciossu, L., Deutschmann, O., and Warnatz, J., Proc. Combust. Inst. 29:973-980 (2003)

118. Knott, G.M., Jackson, T.L., and Buckmaster, J. AIAA J., 39:678-686 (2001).

119. Kochevets, S., Buckmaster, J., Jackson, T.L., and Hegab, A., J. Prop. Power 17:883-891 (2001).

120. Chen, M., Buckmaster, J., Jackson, T.L., and Massa, L., Proc. Combust. Inst. 29:2923-2929 (2002).

121. Jackson, T.L., and Buckmaster, J., AIAA J. 40:1122-1130 (2002).

122. Hegab, A., Jackson, T.L., Buckmaster, J., and Stewart, D.S., Combust. Flame, 125:1055-1070 (2001). 
123. Massa, L., Jackson, T.L., and Short, M., Combust. Theory Modelling, 7:579$602(2003)$.

124. Massa, L., Jackson, T.L., and Buckmaster, J., J. Propul. Power, in press (2004).

125. Buckmaster, J., Jackson, T.L., Massa, L., and Ulrich, M., Proc. Combust. Inst., 30, in press, (2004).

126. Massa, L., Jackson, T.L., and Buckmaster, J., AIAA J., in press, (2004).

127. Wang, X., Jackson, T.L., and Massa, L., Combust. Theory Modelling, 8:227254 (2004).

128. Wang, X., and Jackson, T.L. The numerical simulation of two-dimensional aluminized composite solid propellant combustion. (submitted) (2004).

129. Jackson, T.L., Najjar, F., and Buckmaster, J. A new class of agglomeration models for aluminum composite propellants based on random packs, and their use for solid propellant rocket motor simulations. (submitted) (2004).

130. Violi, A., Yan, S., Eddings, E.G., Sarofim, A., Granata, S., Faravelli, T., and Ranzi, E., Combust. Sci. Technol. 174:3990417 (2002).

131. Burcat, A., Scheller, K., and Lifshitz, A., Combust. Flame 16:29-33 (1971).

132. Westbrook, C.K., and Pitz, W.J., Ind. Eng. Chem. Prod. Res. Dev. 25:159-162 (1986).

133. Ciezki, H., and Adomeit, G., Combust. Flame 93:421-423 (1993).

134. Fieweger, K., Blumenthal, R., and Adomeit, G., Combust. Flame 109:599-619 (1997).

135. Minetti, R., Carlier, M., Ribaucour, M., Therssen, E., and Sochet, L.R., Combust. Flame 102:298-309 (1995).

136. Curran, H.J., Gaffuri, P., Pitz, W.J., and Westbrook, C.K., Combust. Flame 129:253-280 (2002).

137. Lifshitz, A., Handbook of Shock Waves 3:211-256 (2001).

138. Matsui, H., and Lee, J.H., Proc. Combust. Inst. 17:1269 (1979).

139. Westbrook, C.K., Combust. Flame 46:191-210 (1982).

140. Westbrook, C.K., Proc. Combust. Inst. 19:127-141 (1982). 
141. Romano, M.P., Radulescu, M.I., Higgins, A.J., Lee, J.H.S., Pitz, W.J., and Westbrook, C.K., Proc. Combust. Inst. 29:2833-2838 (2002).

142. Kailasanath, K., Oran, E.S., Boris, J.P., and Young, T.R., Combust. Flame 61:199-209 (1985).

143. Oran, E.S., Weber, J.W., Stefaniw, E.I., Lefebvre, M.H., and Anderson, J.D., Combust. Flame 113:147-163 (1998).

144. Keller, J.O., and Westbrook, C.K., Proc. Combust. Inst. 21:547-555 (1986).

145. Keller, J. O., Bramlette, T. T., Dec, J. E., and Westbrook, C. K., Combust. Flame 75:33-44 (1989).

146. Barr, P. K., Keller, J. O., Bramlette, T. T., Westbrook, C. K., and Dec, J. E., Combust. Flame 82:252-269 (1990).

147. Keller, J.O., Bramlette, T.T., Barr, P.K., and Alvarez, J.R., Combust. Flame 99:460-466 (1994).

148. Workshop on the Numerical Simulation of Combustion for Application to Spark and Compression Ignition Engines, La Jolla, CA, National Science Foundation Rann Program, 1975.

149. Lund, C.M., "HCT - A general computer program for calculating timedependent phenomena involving one-dimensional hydrodynamics, transport, and detailed chemical kinetics, Lawrence Livermore Laboratory report UCRL-52504 (1978).

150. Westbrook, C.K., Adamczyk, A.A., and Lavoie, G.A., Combust. Flame 40:81-99 (1981).

151. Hocks, W., Peters, N., and Adomeit, G., Combust. Flame 41:157-170 (1981).

152. Blint, R.J., and Bechtel, J.H., Combust. Sci. Technol. 27:87-95 (1982).

153. Hamrin, D.A., and Heywood, J.B., Society of Automotive Engineers report SAE-950984 (1995).

154. Vosen, S.R., Greif, R., and Westbrook, C.K., Proc. Combust. Inst. 20:75-83 (1984).

155. Poinsot, T., Haworth,D., and Bruneaux, G., Combust. Flame 95:118-133 (1993).

156. Bruneaux, G., Akselvoll, K., Poinsot, T., and Ferziger, J., Combust. Flame 107:27-44 (1996).

157. Alshaalan, T., and Rutland, C., Proc. Combust. Inst. 27:393-399 (1998). 
158. Popp, P., Smooke, M., and Baum, M., Proc. Combust. Inst. 26:2693-2700 (1996).

159. Popp, P., and Baum, M., Combust. Flame 108:327-348 (1997).

160. Lancaster, D.R., Inst. Mech. Eng. C397/ 80 (1980).

161. Westbrook, C.K., Acta Astron. 5:1185-1198 (1978).

162. Quader, A.A., Society of Automotive Engineers report SAE-760760 (1976).

163. Smith, O.I., Sawyer, R.F., and Westbrook, C.K., Proc. Combust. Inst. 17:1305-1313 (1978).

164. Lovell, W.G., Indust. Engin. Chem. 40:2388-2438 (1948).

165. Midgley, T., and Boyd, T.A., Indust. Engin. Chem. 14:894-898 (1922).

166. Boyd, T.A., SAE Quarterly Transactions 4:182-195 (1950).

167. Westbrook, C.K., Pitz, W.J., and Leppard, W.R., Society of Automotive Engineers report SAE-912314 (1991).

168. Griffiths, J.F., HalfordMaw, P.A., and Mohamed, C., Combust. Flame 111:327-337 (1997).

169. Lemaire, O., Ribaucour, M., Carlier, M., and Minetti, R., Combust. Flame 127:1971-1980 (2001).

170. Held, T.J., Marchese, A.J., and Dryer, F.L., Combust. Sci. Technol. 123:107146 (1997).

171. Leppard, W.R., Combust. Sci. Technol. 43:1-20 (1985).

172. Cernansky, N. P., Green, R. M., Pitz, W. J., and Westbrook, C. K., Combust. Sci. Technol. 50:3-25 (1986).

173. Smith, J. R., Green, R. M., Westbrook, C. K., and Pitz, W. J., Proc. Combust. Inst. 20:91-100 (1984).

174. McEnally, C., Ciuparu, D.M., and Pfefferle, L., Combust. Flame 134:339-353 (2003).

175. Silke, E., Curran, H.J., and Simmie, J.M., Proc. Combust. Inst. 30:xx-xx (2004).

176. Faeth, G.M., Proc. Combust. Inst. 26:1593-1612 (1996). 
177. Kim, W.T., and Huh, K.Y., Proc. Combust. Inst. 29:569-576 (2002).

178. Bilger, Phys. Fluids A 5:436-444 (1993).

179. Marchese, A.J., Dryer, F.L., Nayagam, V., and Colantonio, R.O., Proc. Combust. Inst. 26:1219-1226 (1996).

180. Kono, M., Ito, K., Niioka, T., Kadota, T., and Sato, J., Proc. Combust. Inst. 26:1189-1199 (1996).

181. Dec, J.E., “A Conceptual Model of DI Diesel Combustion Based on LaserSheet Imaging", Society of Automotive Engineers report SAE-970873 (1997).

182. Flynn, P.F., Durrett, R.P., Hunter, G.L., zur Loye, A.O., Akinyemi, O.C., Dec, J.E., and Westbrook, C.K., Society of Automotive Engineers report SAE-1999-01-0509 (1999).

183. Wang, H., and Frenklach, M., Combust. Flame 110:173-221 (1997).

184. Daly, D., Society of Automotive Engineers report SAE-2001-01-0653 (2001).

185. Miyamoto, N., Ogawa, H., Nurun, N.M., Obata, K., and Arima, T., Society of Automotive Engineers report SAE-980506 (1998).

186. Fisher, E. M., Pitz, W. J., Curran, H. J., and Westbrook, C. K., Proc. Combust. Inst. 28: 1579-1586 (2000).

187. Mueller, C.J., Pitz, W.J., Pickett, L.M., Martin, G.C., Siebers, D.L., and Westbrook, C.K., Society of Automotive Engineers report SAE-2003-011791 (2003).

188. Violi, A., Kubota, A., Truong, T.N., Pitz, W., Westbrook, C.K., and Sarofim, A.F., Proc. Combust. Inst. 29:2343-2349 (2002).

189. Christensen, M., Johansson, B., and Einewall, P., Society of Automotive Engineers report SAE-972874 (1997).

190. Christensen, M., and Johansson, B., Society of Automotive Engineers report SAE-972874 (1997).

191. Christensen, M., Hohansson, B., Amneus, P., and Mauss, F., Society of Automotive Engineers report SAE-980787 (1998).

192. Noda, T., and Foster, D.E., Society of Automotive Engineers report SAE2001-01-0250 (2001). 
193. Fiveland, S.B., and Assanis, D.N., Society of Automotive Engineers report SAE-2001-01-1028 (2001).

194. Aceves, S.M., Flowers, D.L., Espinosa-Losa, F., Martinez-Frias, J., Dec, J.E., Sjöberg, M., Dibble, R.W., and Hessel, R.P., Society of Automotive Engineers report SAE-2004-01-1910 (2004).

195. Fiveland, S.B., Christensen, M., Johansson, B., Mauss, F., Hiltner, J., Agama, R., and Assanis, D.N., Society of Automotive Engineers report SAE-01FL-524 (2001).

196. Aceves, S., Flowers, D.L., Westbrook, C.K., Smith, J.R., Pitz, W.J., Dibble, R., Christensen, M., and Johansson, B ., Society of Automotive Engineers report SAE-2000-01-0327 (2000).

197. Yokokawa, M., Itakura, K., Uno, A., Ishihara, T., Kaneda, Y., Proc. IEEE/ACM SC2002, 16-22 (2002).

198. Abe, H., Kawamura, H., Matsuo, H., Int. J. Heat and Fluid Flow 25:404-419 (2004).

199. Iwamoto, K., Kasagi, N., Suzuki, Y., Dynamical Roles of Large-Scale Structures in Turbulent Channel Flow, 6th World Congress on Computational Mechanics, Beijing, Sep. 2004, to appear.

200. Tanahashi M., Fujimura M., and Miyauchi T., Proc. Combust. Inst. 28:529535 (2000).

201. Nishiki, S., Hasegawa, T., Borghi, R., Himeno, R., Proc. Combust. Inst., 29:2017-2022 (2002).

202. Mizobuchi, Y., Tachibana, S., Shinjo, J., Ogawa, S., Takeno, T, Proc. Combust. Inst., 29:2009-2015 (2002).

203. Mizobuchi, Y., Shinjo, J., Ogawa, S., Takeno, T., Understanding of Combustion Phenomena in a Hydrogen Jet Lifted Flame by Use of DNS with Hundred Millions of Grid Points, 6th World Congress on Computational Mechanics, Beijing, Sep. 2004, to appear.

204. Cheng, T. S., Wehrmeyer, J. A., Pitz, R. W., Combust. Flame, 91:323-345 (1992).

205. Westbrook, C. K., Combust. Sci. Tech., 29:67-81 (1982).

206. Chapman, S., Cowling, T. G., The Mathematical Theory of Non-Uniform Gases, Cambridge University Press, Cambridge (1970).

207. Wilke, C. R, J. Chem. Phys (1950), 18(4):517-519. 
208. Stull, D. R. et al., JANAF Thermochemical Tables, Cleaninghouse for Federal Scientific and Technical Information, Washington D.C. (1965).

209. Kee, R. J., Grcar, J. F., Smooke, M. D., Miller, J. A., Sandia report sand 858240, Sandia National Laboratory(1985).

210. Roe, P. L., J. Comp. Phys., 43:357-372 (1981).

211. Wada, Y., Ogawa, S., Ishiguro, T., AIAA paper 89-0202 (1989).

212. Wada, Y., Numerical Simulation of High-Temperature Gas Flows by Diagonalization of Gasdynamic Matrices, PhD thesis, the University of Tokyo (1995).

213. Mizobuchi,Y., Ogawa, S., AIAA paper 2000-0184 (2000).

214. Thompson, K. W., J. Comp. Phys., 68:1-24 (1987).

215. Poinsot, T. J., Lele, S. K., J. Comp. Phys., 101:104-129 (1992).

216. Yamashita, H., Shimada, M., Takeno, T., Proc.Combust. Inst., 26:2)7-34 (1996.

217. Bilger, R. W., Proc.Combust. Inst., 22:475-488 (1988).

218. Williams, F. A., Combustion theory. Benjamin Cummings, Menlo Park, CA, 1985.

219. Pope, S. B., Proc. Combust. Inst. 23:591-612, (1990).

220. Poinsot, T. and Veynante, D., "Theoretical and numerical combustion" R.T. Edwards, Philadelphia, 2001.

221. Spalding, D. B., Proc. Combust. Inst. 13:649-657 (1971).

222. Poinsot, T., Candel, S. and Trouvé, A., Prog. Energy Combust. Sci. 21: 531576 (1996).

223. Poinsot, T., Proc. Combust. Inst. 26: 219-232 (1996).

224. Vervisch, L. and Poinsot, T., Ann. Rev. Fluid Mech. 30: 655-692 (1998).

225. Marble, F. E., Adv. in Aerospace Science :395-413 (1985).

226. Karagozian, A. R. and Marble, F. E., Combust. Sci. Technol. 46:65-84 (1986).

227. Rutland, C. J. and Ferziger, J., Combust. Flame 84: 343-360 (1991).

228. Poinsot, T., Veynante, D. and Candel, S., J. Fluid Mech. 228: 561-605 (1991) 
229. Ashurst, W. T. and Barr, P. K., Combust. Sci. Technol. 34: 227-256 (1983).

230. Ashurst, W. T., Kerstein, A. R., Kerr, R. M. and Gibson, C. H., Phys. Fluids 30: 2343-2353 (1987).

231. Rutland, C. J. and Trouvé, A., Combust. Flame 94:41-57 (1993).

232. Bruneaux, G., Akselvoll, K., Poinsot, T. and Ferziger, J., Comb. Flame 107: 27-44 (1996).

233. Alshaalan, T. and Rutland, C. J., Proc. Combust. Inst. 27: 793-799 (1998)

234. Cattolica, R. J. and Vosen, S. R., Comb. Sci. Tech.48: 77 (1986)

235. Roberts, W. L. and Driscoll, J. F., Comb. Flame 87: 245-256 (1991).

236. Driscoll, J. F., Sutkus, D., Roberts, W. L., Post, M. and Goss, Comb. Sci. Tech. 96: 213-229 (1994).

237. Samaniego, J. M. and Mantel, T., Comb. Flame 118: 537-556 (1999).

238. Yeung, P. K., Girimaji, S. S. and Pope, S. B., Comb. Flame 118: 537-556 (1999).

239. Meneveau, C. and Poinsot, T., Comb. Flame 86: 311-332 (1991).

240. Bruneaux, G., Poinsot, T. and Ferziger, J., J. Fluid Mech. 349: 191-219 (1997).

241. Baum, M., Poinsot, T., Haworth, D. and Darabiha, N., J. Fluid Mech. 281: 132 (1994).

242. Chen, J. H., Echekki, T. and Kollman, W., Comb. Flame 116: 15-48 (1998).

243. Vervisch, L., Hauguel, R., Domingo, P. and Rullaud, M., J. of Turb. 5: 004 (2004)

244. Candel, S., Proc. Combust. Inst. 24:1277-1296 (1992).

245. McManus, K., Poinsot, T. and Candel, S., Prog. Energy Comb. Sci. 19: 1-29 (1993).

246. Selle, L., Lartigue, G., Poinsot, T., Koch, R., Schildmacher, K.-U., Krebs, W., Kaufmann, P. and Veynante, D., Comb. Flame, 137, 4, 489-505 (2004).

247. Colin, O. and Rudgyard, M., J. Comp. Phys.162: 338-371 (2000). 
248. Mahesh, K., Constantinescu, G., Apte, S., Iaccarino, G., Ham, F. and Moin, P., Annual Research Briefs, Center for Turbulence Research, NASA Ames/Stanford Univ., 2002, p. 115-142.

249. Oran, E.S., and Boris, J.P., Numerical Simulation of Reactive Flow, Elsevier, New York, 1987.

250. Numerical Approaches to Combustion Modeling, E.S. Oran and J.P. Boris, eds., vol. 135 in Progress in Astronautics and Aeronautics, American Institute of Aeronautics and Astronautics, Washington, DC, 1991.

251. Bracco, F.V., "Introducing a New Generation of More Detailed and Informative Combustion Models", Society of Automotive Engineers report SAE-741174 (1974).

252. Bracco, F.V., Gupta, H.C., Krishnamurthy, L., Santavicca, D.A., Steinberger, R.L., and Warshaw, V., “Two-Phase, Two-Dimensional, Unsteady Combustion in Internal Combustion Engines; TheoreticalExperimental Results", Society of Automotive Engineers report SAE760114 (1976).

253. Bracco, F.V., "Modeling of Engine Sprays", Society of Automotive Engineers report SAE-850394 (1985). 